\title{
A Piecewise Yield Failure Criterion including the Critical State for Brittle Rock
}

\author{
Jing Zhang $\mathbb{D}^{1},{ }^{1}$ Fengyu Ren $\mathbb{D}^{1},{ }^{1}$ Zhihua Ouyang $\mathbb{D}{ }^{2}$, and Huan Liu $\mathbb{D}^{1}$ \\ ${ }^{1}$ Department of Resources and Civil Engineering, Northeastern University, Shenyang 110819, China \\ ${ }^{2}$ Department of Resources and Environmental Engineering, Wuhan University of Science and Technology, Wuhan 430081, China \\ Correspondence should be addressed to Jing Zhang; yuanzhongni33@163.com
}

Received 3 January 2020; Revised 7 August 2020; Accepted 15 October 2020; Published 15 December 2020

Academic Editor: Weerachart Tangchirapat

Copyright (c) 2020 Jing Zhang et al. This is an open access article distributed under the Creative Commons Attribution License, which permits unrestricted use, distribution, and reproduction in any medium, provided the original work is properly cited.

The critical state of rock is an important index for measuring the changes in rock characteristics. However, this state is not unique because of the different researcher assumptions. Based on the theory of the partial differential equation proposed by Vutukuri, according to Mohr's envelope, a piecewise yield failure criterion (referred to as the Mohr-Wedge criterion), including the critical state for brittle rock, is obtained by introducing the wedge model to solve this equation. The Mohr-Wedge (M-W) criterion consisting of nonlinear and linear components includes the critical state for brittle rock. When the minimum principal stress $\sigma_{3}$ is lower than the confining pressure $\sigma_{k}$, the maximum principal stress $\sigma_{1}$ varies nonlinearly with $\sigma_{3}$; otherwise, $\sigma_{1}$ varies linearly with $\sigma_{3}$. This variation conforms to rock deformation features under triaxial compression. In this study, we investigate the rationality of this critical state by an analogy method and illustrate that the critical state mentioned in this criterion is related to the microcracks in the potential failure zone of the rock. Alternatively, the primary object of this study is to reveal the applicability of predicting the yield state for this criterion. The method used in our study is compared to the Mohr-Coulomb (M-C) criterion, the Hoek-Brown (H-B) criterion, and the Exponential (Exp.) criterion by the yield surfaces on the deviatoric plane. Notably, there is a vertex consistent region for the four criteria, but except for this region, the yield state of rock predicted by the four criteria is quite different, depending on the extent of the parameters for the criteria and the magnitude of the slopes of the yield surfaces. The results show that the M-W criterion has certain applicability for predicting the rock yield state by using the multiple data of rock triaxial compression tests in the published literature.

\section{Introduction}

The failure criterion, one of the basic theoretical problems in geotechnical mechanics, has been a research hotspot and has important guiding significance for actual geotechnical engineering. The Coulomb criterion proposed that rock failure is mainly a shear failure, and the shear stress $\tau$ follows a positive proportion to the normal stress failure $\sigma$ on the failure shear plane [1]. Through many experimental studies, Mohr [2] proposed that $\tau$ and $\sigma$ should be expressed by a functional relationship $\tau=f(\sigma)$, namely, the Mohr envelope. The formulation of the Mohr envelope provided substantial assistance for numerous scholars to study the failure criterion. Subsequently, Balmer [3] proposed that the nonlinear envelope can be represented by the maximum principal stress $\sigma_{1}$ and the minimum principal stress $\sigma_{3}$. Using that conclusion, Ucar [4] and Kumar [5] successively obtained the expressions of the shear envelope of the narrow $\mathrm{H}-\mathrm{B}$ criterion [6] and generalized Hoek-Brown (H-B) criterion [7]. In addition, most scholars [8-14] proposed many available triaxial failure criteria for brittle rock based on experimental observation or theoretical analysis. The applicability of these criteria was mainly discussed in the principal stress plane.

Based on the research of Balmer [3], Vutukuri [15] deduced the partial differential equation of stresses by introducing the rock failure angle and envelope slope angle, which proved that the envelope slope angle $\partial \tau_{\Phi} / \partial \sigma_{\Phi}$ is related to the axial-radial stress curve slope angle $\partial \sigma_{1} / \partial \sigma_{3}$. Ouyang and Elsworth [16] utilized a partial differential 
equation of stresses to propose a phenomenological rock failure criterion, which was a theoretical formula based on the brittle failure of rock in the microshear test, and the wedge model was a rock failure model based on the developmental vertical and horizontal microcracks on the shear potential failure zone $[17,18]$.

The Mohr-Wedge (M-W) yield failure criterion, a theoretical derivation based on microscopic experiments, is a piecewise function including the critical state for brittle rock. The characteristics of rock under different confining pressures are determined by many factors, such as the rock type, earth pressure, and joint. Clearly, the deformation and failure modes of a deep rock mass are different from those of a shallow rock mass [19]. Matthew et al. [20] presented four failure modes for rock slopes, namely, sliding, toppling, slumping, and confined slumping. For the rock critical state, Sankhaneel and Gabriel [21] proposed that the failure of rock is extensile cracking under low confinement conditions and semibrittle shear under higher confinement conditions. In addition, some scholars suggested that the variation in the principal stress is linear under low confining pressure and nonlinear under high confining pressure [22, 23]. However, the $\mathrm{M}-\mathrm{W}$ criterion reveals a nonlinear relationship under low confining pressure due to the influence of internal microcracks of rock. When the microcracks in the shear potential failure zone are compacted, the variation in the stress is linear under a very high confining pressure due to instantaneous linear elastomer outside the shear potential failure zone.

In the following sections, we compare the $\mathrm{M}-\mathrm{W}$ yield criterion with the Mohr-Coulomb (M-C) criterion [2], the $\mathrm{H}-\mathrm{B}$ criterion [7], and the Exponential (Exp.) criterion [12] to discuss the rationality of the failure model and the applicability of the criterion. Except for comparing the variation in the principal stress and arranging the parameters of the criterion, we discuss the yield surfaces on the deviatoric plane detailedly. Taking into account the principle of the coordinate invariance of plasticity theory, the description of the yield behavior is not affected by the choice of the coordinate system [24-26]. Consequently, we can obtain the yield surfaces on the deviatoric plane through the coordinate transformation of the deviatoric plane and principal stress space, which transform the three-dimensional yield problem of the principal stress space into the deviatoric plane. Finally, we compared the accuracy of the predicting rock yield state among the three criteria with the triaxial compression test data.

\section{Criterion Features}

The M-W criterion proposed by Ouyang and Elsworth can be summarized as follows [16]:

$$
\tau_{m}=\left\{\begin{array}{lc}
\frac{1}{A} \ln \left[\sqrt{1+A^{2}\left(\sigma_{m}+W_{1} / 2 B\right)^{2}}+A\left(\sigma_{m}+\frac{W_{1}}{2 B}\right)\right]+\frac{\sigma_{t}}{2}, & -\frac{W_{1}}{2 B} \leq \sigma_{m} \leq \frac{1-W_{1}}{2 B} \\
-\cos 2 \Phi^{0} \sigma_{m}+C, & \sigma_{m}>\frac{1-W_{1}}{2 B},
\end{array}\right.
$$

where $\tau_{m}=\left(\sigma_{1}-\sigma_{3}\right) / 2, \quad \sigma_{m}=\left(\sigma_{1}+\sigma_{3}\right) / 2, \quad A=-2 K_{2} B / K_{1}$, $K_{1}=4 /(\pi+2)$, and $K_{2}=4 /(\pi-2)$. The variables $\sigma_{1}, \sigma_{3}$, and $\sigma_{t}$ represent the maximum principal stress, minimum principal stress, and uniaxial tensile strength, respectively. $C=\tau_{m}^{0}+\cos 2 \Phi^{0}\left[\left(1-W_{1}\right) / 2 B\right]$, in which $\tau_{\mathrm{m}}^{0}$ and $\Phi^{0}$ are the value of equation (1) and the rock failure angle at $\sigma_{m}=\left(1-W_{1}\right) / 2 B$, respectively. The constant $W_{1}$ is the number of cracks per unit volume, and $B$ is the parameter associated with an elliptical crack. The physical significance of the specific parameters is detailed in [16].

Obviously, the $\mathrm{M}-\mathrm{W}$ criterion is a piecewise function consisting of nonlinear and linear components. The critical state between the two components is that the microcracks outside the potential failure zone of the rock sample are compacted. Taking $\sigma_{k}$ as the critical confining pressure, Figure 1 shows the variation in the relationship between $\sigma_{1}$ and $\sigma_{3}$. When $\sigma_{3} \leq \sigma_{k}, \sigma_{1}$ varies nonlinearly with $\sigma_{3}$ because of the microcracks, and when $\sigma_{3}>\sigma_{k}$, the microcracks are compacted, $\sigma_{1}$ varies linearly with $\sigma_{3}$, and the rock sample presents as a linear elastic material. This variation conforms to rock deformation features under triaxial compression.
In addition, the $\mathrm{H}-\mathrm{B}$ criterion [7] also can illustrate the change relationships between $\sigma_{1}$ and $\sigma_{3}$. The expression of the $\mathrm{H}-\mathrm{B}$ criterion is as follows:

$$
\sigma_{1}=\sigma_{3}+\sigma_{\mathrm{c}} \sqrt{\frac{m \sigma_{3}}{\sigma_{\mathrm{c}}}+1}
$$

where $\sigma_{\mathrm{c}}$ is the uniaxial compression strength and $m$ is the experience parameter.

The value of $\mathrm{d} \sigma_{1} / \mathrm{d} \sigma_{3}$ can be derived from equation (2) as follows:

$$
\frac{\mathrm{d} \sigma_{1}}{\mathrm{~d} \sigma_{3}}=1+\frac{m}{2 \sqrt{m \sigma_{3} / \sigma_{\mathrm{c}}+1}} .
$$

The variation in the relationship between $\sigma_{1}$ and $\sigma_{3}$ is nonlinear under low confining pressure. However, when confining pressure $\sigma_{3}$ is infinite, the value of $\mathrm{d} \sigma_{1} / \mathrm{d} \sigma_{3}$ is approximately equal to 1 , which indicates that the relationship is approximately linear. Therefore, the variation in the relationship between $\sigma_{1}$ and $\sigma_{3}$ in the M-W criterion is similar to the H-B criterion. 


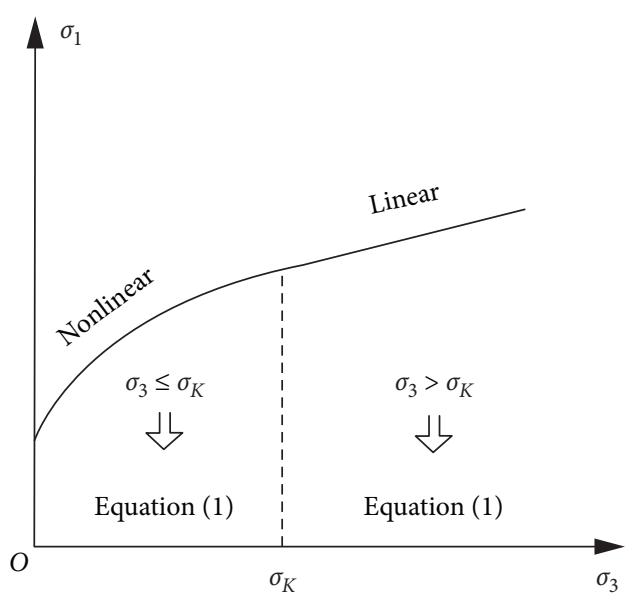

FIGURE 1: Variation in the principal stress for the M-W criterion.

2.1. Wedge Model. The wedge model is a rock failure model based on the development of vertical and horizontal microcracks in the shear potential failure zone [16]. There are two features. (1) When the rock bears a load, the force transfer through the potential failure zone must be concentrated on the wedge vertices (similar to the concentrated forces $P_{1}$ and $P_{2}$ shown in Figure 2) due to the influence of the microcracks. Therefore, the ratio of the sum of all the concentrated forces $P_{1}$ and $P_{2}$ to their respective areas is equal to the normal stress $\sigma_{\Phi}$ and shear stress $\tau_{\Phi}$ on the macroscopic failure surface of the rock. (2) The rock shear failure can be regarded as the value of the shear stress maximum on the macroaspect. Moreover, the shear failure can also be regarded as the tensile stress (the tensile stress is negative) at the boundary of the wedge particles when the potential failure attains a minimum on the microaspect. The second feature represents the boundary conditions for solving the expression of the rock failure angle $\Phi$ and principal stress; the detailed derivation process is described in [16].

2.2. Physical Meaning of the Parameters. Considering that the vast parameters in the criterion may be adverse to practical applications, the parameters are arranged first.

(1) Parameters of $K_{1}$ and $K_{2}$

We introduce $K$ instead of $K_{1}$ and $K_{2}$ because the dimensions of $K_{1}$ and $K_{2}$ are 1 as follows:

$$
K=\frac{K_{2}}{K_{1}}=\frac{\pi+2}{\pi-2}
$$

(2) Parameters of $W_{1}$ and $\sigma_{t}$

Reference [16] provides the following secondary function:

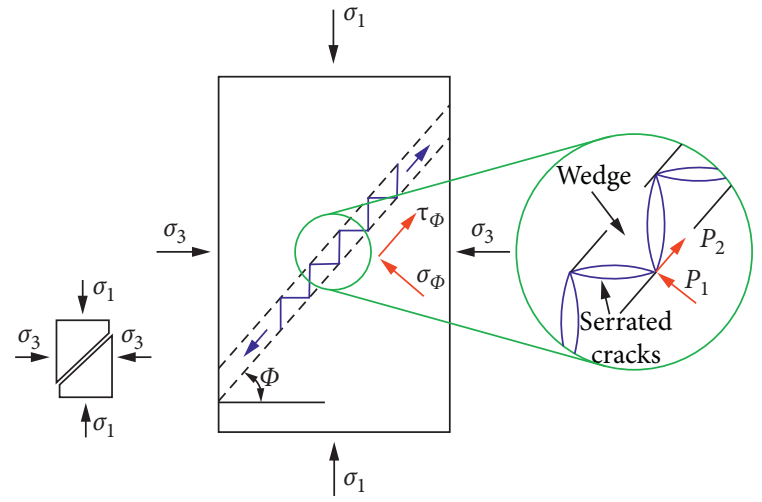

FIGURE 2: The microcrack distribution pattern of the potential failure zone in the wedge model [16].

$$
W= \begin{cases}B\left(\sigma_{1}+\sigma_{3}\right)+W_{1}, & -\frac{W_{1}}{B} \leq \sigma_{1}+\sigma_{3} \leq \frac{\left(1-W_{1}\right)}{B}, \\ 1, & \sigma_{1}+\sigma_{3}>\frac{\left(1-W_{1}\right)}{B},\end{cases}
$$

where $W$ represents the particle stress concentration factor.

The upper limit of equation (5) actually represents the uniaxial tension of the rock. Then, for $\sigma_{1}=-\sigma_{t}$ and $\sigma_{3}=0$, the uniaxial tensile strength $\sigma_{t}$ can be shown as follows:

$$
\sigma_{t}=\frac{W_{1}}{B}
$$

(3) Parameters of $A, B, W$, and $\Phi$

The equation between $W$ and $\Phi$ can be found in [16] as follows:

$$
\tan 2 \Phi=-\frac{K_{2}}{K_{1}} W,
$$

where $\Phi$ represents the rock failure angle.

The observed dimensions of the parameters are as follows: $A$ and $B$ are $\mathrm{M}^{-1} \mathrm{LT}^{2}$, and $W$ and $\Phi$ are 1 . Then, referring to the M-C criterion and $\mathrm{H}-\mathrm{B}$ criterion, the dimensions of both parameters are divided into two types, namely, $\mathrm{ML}^{-1} \mathrm{~T}^{-2}$ and 1 . However, dimension 1 is not an appropriate parameter to integrate the parameters $(A, B, W$, and $\Phi)$. Ultimately, we introduced the parameter $\sigma_{w}$ (the dimension is $\mathrm{ML}^{-1} \mathrm{~T}^{-2}$ ) as follows: 


$$
\sigma_{w}=-\frac{1}{A}
$$

Substituting equations (5) and (7) and $A=-2 K_{2} B / K_{1}$ into equation (8) and rearranging the equation yield

$$
\sigma_{w}=-\frac{\left(\sigma_{1}^{*}+\sigma_{3}^{*}+\sigma_{t}\right)}{2 \tan 2 \Phi^{*}}
$$

where $\sigma_{1}^{*}$ and $\sigma_{3}^{*}$ are the triaxial test data of a group of rock samples and $\Phi^{*}$ is the rock failure angle when the confining pressure is $\sigma_{3}^{*}$.

Substituting equations (4), (6), and (9) into equation (1) gives

$$
\tau_{m}= \begin{cases}-\sigma_{w} \ln \left[\sqrt{1+\left(\frac{2 \sigma_{m}+\sigma_{t}}{2 \sigma_{w}}\right)^{2}}-\left(\frac{2 \sigma_{m}+\sigma_{t}}{2 \sigma_{w}}\right)\right]+\frac{\sigma_{t}}{2}, & -\frac{\sigma_{t}}{2} \leq \sigma_{m} \leq K \sigma_{w}-\frac{\sigma_{t}}{2} \\ -\cos 2 \Phi^{0} \sigma_{m}+C, & \sigma_{m}>K \sigma_{w}-\frac{\sigma_{t}}{2}\end{cases}
$$

Although the $\mathrm{M}-\mathrm{W}$ criterion parameters are integrated, the physical meaning of $\sigma_{w}$ is unclear. Actually, we can obtain another expression for $\sigma_{w}$ from [16]. The expression of $B$ is as follows:

$$
B=\frac{h a\left(1-v^{2}\right)}{(E b)}
$$

where $h$ is the microcracks density, $a$ is the major semiaxis of the ellipse microcrack, $b$ is the minor semiaxis of the ellipse microcrack, and $E$ and $v$ are the elasticity modulus and Poisson's ratio, respectively.

Substituting equation (11) and $A=-2 K_{2} B / K_{1}$ into equation (8) and rearranging the equation yield

$$
\sigma_{w}=N \frac{E}{1-v^{2}},
$$

where $N=b /(2 K h a)$.

Substituting $G=E / 2(1+v)$ into equation (12) and rearranging the equation yield

$$
\sigma_{w}=N \frac{4 G^{2}}{4 G-E},
$$

where $G$ is the shear modulus.

As for equation (13), we suggest that $\sigma_{w}$ is related to the elasticity modulus, shear modulus, and parameter $N$, which contain the density and the eccentricity of an elliptical microcrack. It follows that the parameter may be defined as the crack modulus, which is a measure of the rock resistance to cracking. In addition, according to the boundary conditions of equation (10), the parameter $K$ is a constant and the value of uniaxial tensile strength $\sigma_{t}$ is generally not larger. Therefore, the parameter $\sigma_{w}$ determines the magnitude of critical confining pressure, that is, the difficulty of the rock entering the critical state.

\section{Test Data and Parameter Calculations}

3.1. Triaxial Compression Test Data of Brittle Rock. The triaxial compression test data of brittle rock are derived from the published literature. Table 1 presents the test data of Dunham dolomite [27], Mizuho trachyte [8], Jinping sandstone [28], Cedar tonalite [29], Carrara marble [30], and Westerly granite [29], which are digitized from [10]. The values of the confining pressure $\sigma_{3}$ in Table 1 are below the critical confining pressure $\sigma_{\mathrm{k}}$. Table 2 presents the strengths of Yamaguchi marble [27], Indiana limestone [31], and Solnhofen limestone [27], which are compressed under various confining pressures and the condition $\sigma_{3}>\sigma_{k}$. The calculation of $\sigma_{k}$ is stated in detail in the next section.

3.2. Parameter Calculation. Given that the comparative analyses between the $\mathrm{M}-\mathrm{W}$ criterion and other criteria are undisposed, we take the $\mathrm{M}-\mathrm{C}$ criterion, $\mathrm{H}-\mathrm{B}$ criterion, and Exp. criterion as the comparison to discuss the applicability of $\mathrm{M}-\mathrm{W}$ criterion.

The expression of $\mathrm{M}-\mathrm{C}$ criterion is as follows:

$$
\sigma_{1}=\frac{1+\sin \phi}{1-\sin \phi} \sigma_{3}+\frac{2 c \cdot \cos \phi}{1-\sin \phi},
$$

where $\varphi$ is the angle of internal friction of the material and $c$ is the cohesion of the material.

The expression of generalized H-B criterion, introduced by Hoek [32], is expressed as

$$
\sigma_{1}=\sigma_{3}+\sigma_{c}\left(m \frac{\sigma_{3}}{\sigma_{c}}+s\right)^{a_{i}},
$$

where $m, s$, and $a_{i}$ are the rock mass material constants, given by 
TABLe 1: Triaxial compression test data $(\mathrm{MPa})$ : all confining pressures $\sigma_{3}$ below the critical confining pressure $\sigma_{k}$.

\begin{tabular}{|c|c|c|c|c|c|}
\hline \multicolumn{2}{|c|}{$\begin{array}{l}\text { Dunham dolomite } \\
\left(\sigma_{k}=435.10 \mathrm{MPa}\right)\end{array}$} & \multicolumn{2}{|c|}{$\begin{array}{l}\text { Mizuho trachyte } \\
\left(\sigma_{k}=198.83 \mathrm{MPa}\right)\end{array}$} & \multicolumn{2}{|c|}{$\begin{array}{l}\text { Jinping sandstone } \\
\left(\sigma_{k}=154.22 \mathrm{MPa}\right)\end{array}$} \\
\hline$\sigma_{3}$ & $\sigma_{1}$ & $\sigma_{3}$ & $\sigma_{1}$ & $\sigma_{3}$ & $\sigma_{1}$ \\
\hline 0.0 & 257.0 & 0.0 & 100.0 & 0.0 & 61.6 \\
\hline 25.0 & 400.0 & 15.0 & 193.0 & 5.0 & 109.5 \\
\hline 45.0 & 488.0 & 30.0 & 253.0 & 10.0 & 138.6 \\
\hline 65.0 & 568.0 & 45.0 & 300.0 & 20.0 & 174.6 \\
\hline 85.0 & 624.0 & 60.0 & 339.0 & 30.0 & 209.0 \\
\hline 105.0 & 679.0 & 75.0 & 365.0 & 40.0 & 240.5 \\
\hline \multirow[t]{3}{*}{125.0} & 724.0 & 100.0 & 419.0 & 50.0 & 263.0 \\
\hline & & & & 60.0 & 288.5 \\
\hline & & & & 70.0 & 305.4 \\
\hline \multicolumn{2}{|c|}{ Cedar tonalite $\left(\sigma_{k}=89.96 \mathrm{MPa}\right)$} & \multicolumn{2}{|c|}{$\begin{array}{l}\text { Carrara marble } \\
\left(\sigma_{k}=217.05 \mathrm{MPa}\right)\end{array}$} & \multicolumn{2}{|c|}{$\begin{array}{l}\text { Westerly granite } \\
\left(\sigma_{k}=851.21 \mathrm{MPa}\right)\end{array}$} \\
\hline$\sigma_{3}$ & $\sigma_{1}$ & $\sigma_{3}$ & $\sigma_{1}$ & $\sigma_{3}$ & $\sigma_{1}$ \\
\hline 0.0 & 13.1 & 0.0 & 137.0 & 0.0 & 201.0 \\
\hline 5.0 & 64.4 & 25.0 & 234.0 & 2.0 & 231.0 \\
\hline 10.0 & 88.9 & 50.0 & 314.0 & 20.0 & 430.0 \\
\hline 20.0 & 112.6 & 68.4 & 358.0 & 38.0 & 612.0 \\
\hline 30.0 & 148.9 & 85.5 & 404.0 & 60.0 & 747.0 \\
\hline 65.0 & 228.4 & 161.8 & 558.0 & 77.0 & 889.0 \\
\hline 75.0 & 248.7 & & & 100.0 & 1012.0 \\
\hline
\end{tabular}

TABle 2: Triaxial compression test data (MPa): part of confining pressure $\sigma_{3}$ above the critical confining pressure $\sigma_{k}$.

\begin{tabular}{|c|c|c|c|c|c|}
\hline \multicolumn{2}{|c|}{$\begin{array}{l}\text { Yamaguchi marble } \\
\left(\sigma_{k}=116.44 \mathrm{MPa}\right)\end{array}$} & \multicolumn{2}{|c|}{$\begin{array}{c}\text { Indiana limestone } \\
\left(\sigma_{k}=40.22 \mathrm{MPa}\right)\end{array}$} & \multicolumn{2}{|c|}{$\begin{array}{l}\text { Solnhofen limestone } \\
\left(\sigma_{k}=146.86 \mathrm{MPa}\right)\end{array}$} \\
\hline$\sigma_{3}$ & $\sigma_{1}$ & $\sigma_{3}$ & $\sigma_{1}$ & $\sigma_{3}$ & $\sigma_{1}$ \\
\hline 0.0 & 81.0 & 0.0 & 44.0 & 0.00 & 293.0 \\
\hline 6.0 & 113.0 & 6.5 & 66.0 & 6.00 & 335.0 \\
\hline 12.5 & 130.0 & 13.7 & 85.0 & 15.00 & 360.0 \\
\hline 25.0 & 175.0 & 20.3 & 99.0 & 24.00 & 381.0 \\
\hline 40.0 & 210.0 & 27.9 & 109.0 & 46.00 & 426.0 \\
\hline 55.0 & 246.0 & 34.4 & 119.0 & 72.00 & 467.0 \\
\hline 70.0 & 272.0 & 41.2 & 128.2 & 111.00 & 518.0 \\
\hline 85.0 & 295.0 & 48.4 & 135.1 & 195.00 & 595.0 \\
\hline 100.0 & 324.0 & 55.4 & 141.9 & 304.00 & 709.0 \\
\hline 150.0 & 397.0 & 62.3 & 149.1 & & \\
\hline 200.0 & 454.0 & 68.4 & 156.5 & & \\
\hline
\end{tabular}

$$
\begin{aligned}
& m=m_{i} \exp \left[\frac{(\mathrm{GSI}-100)}{(28-14 D)}\right], \\
& s=\exp \left[\frac{(\mathrm{GSI}-100)}{(9-3 D)}\right], \\
& a_{i}=\frac{1}{2}+\frac{1}{6}\left(e^{-\mathrm{GSI} / 15}-e^{-20 / 3}\right),
\end{aligned}
$$

where GSI is the geological strength index. $D$ is a factor which depends upon the degree of disturbance to which the rock mass has been subjected to blast damage and stress relaxation. For the intact rock, the material constants are denoted by $s=1, a_{i}=0.5$, and $m$. The expression of H-B criterion for intact rock is shown in equation (2).

The $\mathrm{H}-\mathrm{B}$ criterion is widely used in practical engineering. Many researchers have made an improvement on the Hoek-Brown criterion. The latest major revision of the GSI and its use in equations (16)-(18) was made by Hoek et al. [33]. Hoek and Diederichs [34] used the database of rock mass deformation modulus measurements and proposed that the rock mass deformation modulus can be represented as

$$
E_{r m}=E_{i}\left\{0.02+\frac{1-D / 2}{1+\exp [(60+15 D-\mathrm{GSI}) / 11]}\right\},
$$

where $E_{i}$ is the intact rock deformation modulus.

Hoek and Brown [35] summarized the research results of most scholars on the $\mathrm{H}-\mathrm{B}$ criterion and incorporated the rock mass deformation modulus into the criterion and GSI system, which further demonstrated practical applications of the criterion and the GSI system. However, the parameters of criteria in this work are obtained by using the least square method to fit the criteria and triaxial compression test data. Therefore, the applicability of $\mathrm{H}-\mathrm{B}$ criterion under the 
condition of intact rock is discussed to obtain the parameters of $\mathrm{H}-\mathrm{B}$ criterion more easily.

The expression of Exp. criterion is as follows [12]:

$$
\sigma_{1}-\sigma_{3}=Q_{\infty}-\left(Q_{\infty}-Q_{0}\right) \exp \left(-\frac{\left(K_{0}-1\right) \sigma_{3}}{Q_{\infty}-Q_{0}}\right)
$$

where $Q_{0}$ is the uniaxial compressive strength, $Q_{\infty}$ is the limitation of stress deviator when confining pressure approaches infinity, and $K_{0}$ is the ratio of strength increasing with confining pressure at confining pressure of zero.

The parameter values of the four yield failure criteria are shown in Table 3. The parameters of M-C criterion, H-B criterion, and Exp. criterion are determined by using the least square method to fit the criteria and triaxial compression test data, and the determination of $\sigma_{t}$ and $\sigma_{w}$ is similar to these criteria. Here, only the values of $\Phi^{0}$ and $C$ are not obtained. Recall that, in the interpretation of the parameters in equation (1), $\Phi^{0}$ and $C$ are closely related to the critical state where the mean principal stress is $\sigma_{m k}$ and the maximum shear stress is $\tau_{m k}$. Then, the expression of $\sigma_{m k}$ is as follows:

$$
\sigma_{m k}=K \sigma_{w}-\frac{\sigma_{t}}{2}
$$

Substituting the value of $\sigma_{m k}$ into equation (1), the value of $\tau_{m k}$ can be found. Naturally, rearranging equation (1) gives

$$
C=\tau_{m k}+\cos 2 \Phi^{0} \sigma_{m k}
$$

The parameter $\Phi^{0}$ is the rock failure angle at the critical state, which is a constant that combines equation (6) with equation (7). Eventually, taking the values of $\sigma_{m k}, \tau_{m k}$, and $\Phi^{0}$ into equation (22), the value of $C$ can be obtained.

Referring to the calculation formula of $\sigma_{k}$ (as shown in equation (23)), we can easily solve $\sigma_{k}$ on the premise that $\sigma_{m k}$ and $\tau_{m k}$ are known.

$$
\sigma_{k}=\sigma_{m k}-\tau_{m k}
$$

\section{Yield Surface}

Assuming that the rock mass is isotropic, the size of three principal stresses is not unique; then the stress state at any point within the rock mass can be described by the movement surface of the stress point in the principal stress space with axes having the dimensions of the stress $\left(\sigma_{1}, \sigma_{2}\right.$, and $\sigma_{3}$ ). Therefore, the plastic response can be confined to the yield surface, which is the movement surface of the yield stress point. Meanwhile, the yield surface is symmetric to the positive and negative directions of the principal stress axes due to the isotropic mass, which determine the symmetry of the stress offset tensor. Naturally, the space diagonal (as shown in Figure 3) that sets equal angles $(\theta)$ with the three principal stress axes is defined in the principal stress space [36], and $\cos \theta=1 / \sqrt{3}$. Whenever any stress point is on the space diagonal, the values of all three principal stresses are equal.

The yield function has always been investigated by the yield surface plotted in the principal stress space. In fact, the deviatoric plane is the foundation of the yield surface. The deviatoric plane is perpendicular to the space diagonal, and the $\pi$-plane is the deviatoric plane through the origin. We define three orthogonal unit vectors denoted by $\mathbf{n}_{\mathbf{D}}, \mathbf{n}_{\mathbf{E}}$, and $\mathbf{n}_{\mathbf{F}}$, where $\mathbf{n}_{\mathbf{D}}$ (as shown in Figure 3 ) is the unit vector coinciding with the space diagonal and $\boldsymbol{n}_{\boldsymbol{E}}$ and $\boldsymbol{n}_{\boldsymbol{F}}$ are the unit vectors on the deviatoric plane (as shown in Figure 4). Suppose that $\mathbf{e}_{1}, \mathbf{e}_{2}$, and $\mathbf{e}_{\mathbf{3}}$ are the unit basis vectors of the three principal stress axes $\left(\sigma_{1}, \sigma_{2}\right.$, and $\left.\sigma_{3}\right)$, respectively. With the help of the vector cross product, we know that [36]

$$
\begin{aligned}
& \mathbf{n}_{\mathbf{D}}=\frac{1}{\sqrt{3}}(1,1,1)^{T}, \\
& \mathbf{n}_{\mathbf{E}}=\mathbf{e}_{\mathbf{1}} \times \mathbf{n}_{\mathbf{D}}=\frac{1}{\sqrt{2}}(0,-1,1)^{T}, \\
& \mathbf{n}_{\mathbf{F}}=\mathbf{n}_{\mathbf{D}} \times \mathbf{n}_{\mathbf{E}}=\frac{1}{\sqrt{6}}(2,-1,-1)^{T} .
\end{aligned}
$$

Recall that the sizes of the principal stresses are not unique, which indicate that the yield surface is symmetric with respect to the line $\mathrm{AD}, \mathrm{BE}$, and $\mathrm{CF}$. These symmetries divide the deviatoric plane into six segments possessing similar properties (I, II, III, IV, V, and VI as shown in Figure 4$)$. It is hypothesized that $\sigma_{D}, \sigma_{E}$, and $\sigma_{F}$ are the stresses in the direction of $\mathrm{n}_{\mathrm{D}}, \mathrm{n}_{\mathrm{E}}$, and $\mathrm{n}_{\mathrm{F}}$, respectively. Then, the coordinate transformation of the deviatoric plane and principal stress space is as follows [36]:

$$
\left.\begin{array}{l}
\sigma_{D}=\frac{1}{\sqrt{3}}\left(\sigma_{1}+\sigma_{2}+\sigma_{3}\right) \\
\sigma_{E}=\frac{1}{\sqrt{2}}\left(-\sigma_{2}+\sigma_{3}\right) \\
\sigma_{F}=\frac{1}{\sqrt{6}}\left(2 \sigma_{1}-\sigma_{2}-\sigma_{3}\right)
\end{array}\right\},
$$

where $\sigma_{D}, \sigma_{E}$, and $\sigma_{F}$ are proposed to facilitate the study of yield surfaces. $\sigma_{D}$ is the stress on the space diagonal, which is proportional to the mean stress p. $\sigma_{E}$ and $\sigma_{F}$ are the stresses on the deviatoric plane, which are related to the deviatoric stress $q$ [36]. $p$ and $q$ can be expressed as 
TABLE 3: Parameter values of the three yield failure criteria.

\begin{tabular}{|c|c|c|c|c|c|c|c|c|c|c|c|}
\hline \multirow{2}{*}{ Rock types } & \multicolumn{4}{|c|}{ M-W criterion } & \multicolumn{2}{|c|}{$\mathrm{H}-\mathrm{B}$ criterion } & \multicolumn{2}{|c|}{$\mathrm{M}-\mathrm{C}$ criterion } & \multicolumn{3}{|c|}{ Exp. criterion } \\
\hline & $\sigma_{t}(\mathrm{MPa})$ & $\sigma_{w}(\mathrm{MPa})$ & $\Phi^{0}\left(^{\circ}\right)$ & $C(\mathrm{MPa})$ & $m$ & $\sigma_{c}(\mathrm{MPa})$ & $\varphi\left({ }^{\circ}\right)$ & $c(\mathrm{MPa})$ & $Q_{\infty}(\mathrm{MPa})$ & $Q_{0}(\mathrm{MPa})$ & $K_{0}$ \\
\hline Dunham dolomite & 7.05 & 192.77 & 51.26 & 242.16 & 8.22 & 286.58 & 38.61 & 66.72 & 683.85 & 257.00 & 6.51 \\
\hline Mizuho trachyte & 2.09 & 87.60 & 51.26 & 109.37 & 6.63 & 135.42 & 33.39 & 34.75 & 332.19 & 100.00 & 6.79 \\
\hline Jinping sandstone & 0.24 & 67.34 & 51.26 & 83.24 & 8.24 & 89.00 & 32.26 & 26.13 & 243.83 & 61.60 & 7.91 \\
\hline Cedar tonalite & 0.18 & 39.30 & 51.26 & 48.60 & 10.47 & 37.20 & 28.55 & 13.78 & 176.60 & 13.10 & 7.51 \\
\hline Carrara marble & 0.92 & 95.03 & 51.26 & 117.82 & 5.53 & 153.79 & 25.81 & 52.86 & 467.44 & 137.00 & 4.11 \\
\hline Westerly granite & 0.64 & 371.40 & 51.26 & 458.68 & 48.67 & 163.67 & 51.49 & 42.14 & 1286.72 & 201.00 & 12.46 \\
\hline Yamaguchi marble & 2.64 & 51.92 & 51.26 & 65.67 & 4.40 & 97.65 & 29.36 & 26.81 & 236.52 & 81.00 & 4.46 \\
\hline Indiana limestone & 4.18 & 19.36 & 51.26 & 26.44 & 2.97 & 50.24 & 21.16 & 17.31 & 89.43 & 44.00 & 4.02 \\
\hline Solnhofen limestone & 54.23 & 87.67 & 51.26 & 141.17 & 2.77 & 315.86 & 22.55 & 105.48 & 453.90 & 293.00 & 3.29 \\
\hline
\end{tabular}

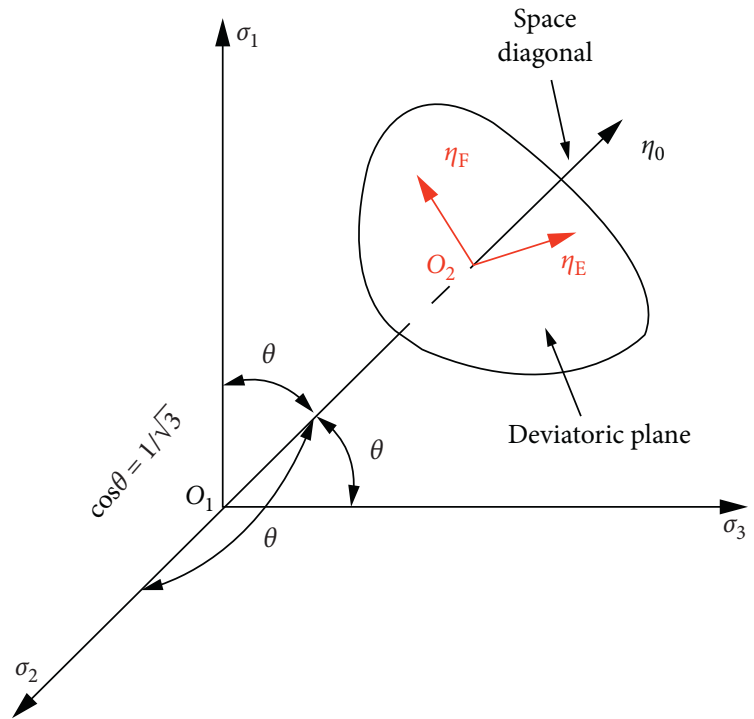

Figure 3: The space diagonal and deviatoric plane in the principal stress space.

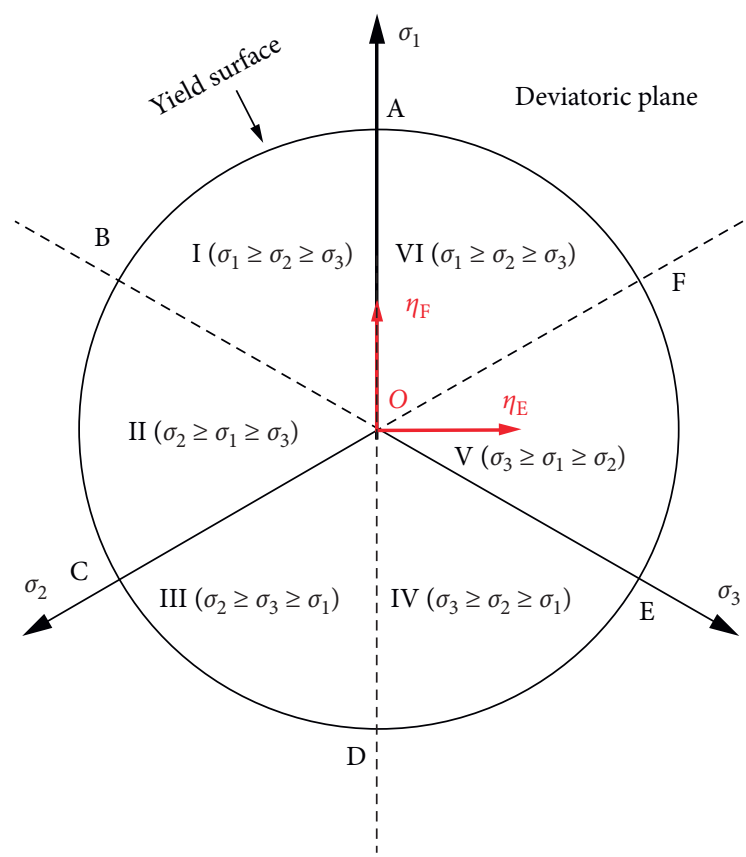

FIGURE 4: Orthogonal unit vectors $\mathrm{n}_{\mathrm{E}}$ and $\mathrm{n}_{\mathrm{F}}$ on the deviatoric plane: looking down the space diagonal. 


$$
\begin{gathered}
p=\frac{\left(\sigma_{1}+\sigma_{2}+\sigma_{3}\right)}{3}, \\
\sqrt{\sigma_{E}^{2}+\sigma_{F}^{2}}=\sqrt{\frac{2}{3}\left(\sigma_{1}^{2}+\sigma_{2}^{2}+\sigma_{3}^{2}-\sigma_{1} \sigma_{2}-\sigma_{2} \sigma_{3}-\sigma_{3} \sigma_{1}\right)}=\sqrt{\frac{2}{3}} q=\sqrt{\frac{2}{3}\left(I_{1}^{2}-3 I_{2}\right)}
\end{gathered}
$$

where $I_{1}$ and $I_{2}$ are, respectively, the first and second principal stress invariants.

4.1. $M-W$ Criterion. To create the form of the yield surface on the deviatoric plane, we invert equation (27):

$$
\left.\begin{array}{l}
\sigma_{1}=\frac{1}{\sqrt{3}} \sigma_{D}+\sqrt{\frac{2}{3}} \sigma_{F} \\
\sigma_{2}=\frac{1}{\sqrt{3}} \sigma_{D}-\frac{1}{\sqrt{2}} \sigma_{E}-\frac{1}{\sqrt{6}} \sigma_{F} \\
\sigma_{3}=\frac{1}{\sqrt{3}} \sigma_{D}+\frac{1}{\sqrt{2}} \sigma_{E}-\frac{1}{\sqrt{6}} \sigma_{F}
\end{array}\right\} .
$$

It is convenient for the M-W criterion to label the piecewise function. We mark the yield surface of equation (10) as $\mathrm{M}-\mathrm{W}-1$ and equation (10) as $\mathrm{M}-\mathrm{W}-2$.

For $\mathrm{M}-\mathrm{W}-1$, substituting equation (30) into equation (10) gives the following.

For the stress area I $\left(\sigma_{1} \geq \sigma_{2} \geq \sigma_{3}\right)$ of Figure 4 ,

$$
\sqrt{6} \sigma_{F}-\sqrt{2} \sigma_{E}+4 \sigma_{w} \ln \left[\sqrt{1+\left(\frac{S_{1}}{2 \sigma_{w}}\right)^{2}}-\frac{S_{1}}{2 \sigma_{w}}\right]=2 \sigma_{t} \text {, }
$$

where $S_{1}=\sigma_{t}+(2 / \sqrt{3}) \sigma_{D}+(1 / \sqrt{2}) \sigma_{E}+(1 / \sqrt{6}) \sigma_{F}$.

For the stress area VI $\left(\sigma_{1} \geq \sigma_{3} \geq \sigma_{2}\right)$ of Figure 4 ,

$$
\sqrt{6} \sigma_{F}+\sqrt{2} \sigma_{E}+4 \sigma_{w} \ln \left[\sqrt{1+\left(\frac{S_{2}}{2 \sigma_{w}}\right)^{2}}-\frac{S_{2}}{2 \sigma_{w}}\right]=2 \sigma_{t} \text {, }
$$

where $S_{2}=\sigma_{t}+(2 / \sqrt{3}) \sigma_{D}+(1 / \sqrt{2}) \sigma_{E}+(1 / \sqrt{6}) \sigma_{F}$.

For the stress area II $\left(\sigma_{2} \geq \sigma_{1} \geq \sigma_{3}\right)$ of Figure 4 ,

$$
-\sqrt{2} \sigma_{E}+2 \sigma_{w} \ln \left[\sqrt{1+\left(\frac{S_{3}}{2 \sigma_{w}}\right)^{2}}-\frac{S_{3}}{2 \sigma_{w}}\right]=\sigma_{t},
$$

where $S_{3}=\sigma_{t}+(2 / \sqrt{3}) \sigma_{D}-(2 / \sqrt{6}) \sigma_{F}$.

Since $\mathbf{n}_{\mathbf{D}}$ is perpendicular to the deviatoric plane and $\sigma_{\mathrm{D}}$ is constant in the deviatoric plane. The expression of $\sigma_{E}$ and $\sigma_{F}$ is shown in equations (31)-(33), which represent the intersection of the yield surface with the stress areas I, IV, and II in Figure 4. To plot the yield surface, we take Solnhofen limestone as an example, and the parameters of the $\mathrm{M}-\mathrm{W}$ yield criterion are shown in Table 3. Equations (31) and (32) are substituted to obtain the coordinate value of A (as shown in Figure 4), which is the crossing point of the yield surface between stress area I and stress area VI. Naturally, the coordinate value of B (as shown in Figure 4) can be obtained, and then the value range of $\sigma_{E}$ in stress area I can be known. Using Equation (31) and the value range of $\sigma_{E}$, the yield surface of stress area I can be obtained. Therefore, referring to the yield surface of stress area I, we can graph the M-W-1 yield surface of the other stress areas (II, III, IV, V, and VI). When $\sigma_{D}=0$, the yield surface is shown in Figure 5(a).

For M-W-2, substituting equation (30) into equation (10) gives the following.

For the stress area I $\left(\sigma_{1} \geq \sigma_{2} \geq \sigma_{3}\right)$ of Figure 4 ,

$$
\begin{aligned}
& \sqrt{6} \sigma_{F}\left(3+\cos 2 \Phi^{0}\right)-3 \sqrt{2} \sigma_{E}\left(1-\cos 2 \Phi^{0}\right) \\
& =12 C-4 \sqrt{3} \sigma_{D} \cos 2 \Phi^{0} .
\end{aligned}
$$

The graphing steps of the M-W-2 yield surface are the same as those of M-W-1. Recall that the M-W yield criterion is a piecewise expression and the yield surface on the threedimensional principal stress space exists as an interface because of $\sigma_{k}$. When $\sigma_{m}=\left(K \sigma_{w}-\sigma_{t}\right) / 2$, we mark the value of the interface (as shown in Figure 6) that intersects with the space diagonal is $\sigma_{D \text { mid. }}$. When $\sigma_{m}=-\sigma_{t} / 2$, the value of $\sigma_{D}$ approaches the minimum and is exhibited as $\sigma_{D \min }$. Substituting these boundary conditions into Equation (27), we can obtain the value of $\sigma_{D \text { min }}$ and $\sigma_{D \text { mid }}$, as shown in Table 4.

As shown in Figure $5(\mathrm{~b})$, when $\sigma_{D \text { min }} \leq \sigma_{D} \leq \sigma_{D \text { mid }}$, the yield surfaces of $\mathrm{M}-\mathrm{W}-1$ that are black polygons varied nonlinearly as a function of $\sigma_{D}$. When $\sigma_{D}>\sigma_{D \text { mid }}$, the yield surfaces of M-W-2 are red irregular hexagons varied linearly as a function of $\sigma_{D}$. When $\sigma_{D}=\sigma_{D \text { mid }}$, the green irregular hexagon is the interface yield surfaces of $M-W-1$ and $\mathrm{M}-\mathrm{W}-2$. This variation trend is consistent with the change in the principal stress in the principal stress space (as shown in Figure 6).

4.2. $M-C, H-B$, and Exp. Criterion. For stress area I $\left(\sigma_{1} \geq \sigma_{2} \geq \sigma_{3}\right)$ of Figure 4, substituting equation (30) into equations (14), (2), and (20) gives the following:

(1) M-C criterion:

$$
-\sqrt{3} \sigma_{E}(1+\sin \phi)+\sigma_{F}(3-\sin \phi)=2 \sqrt{6} c \cos \phi+2 \sqrt{2} \sigma_{D} \sin \phi .
$$




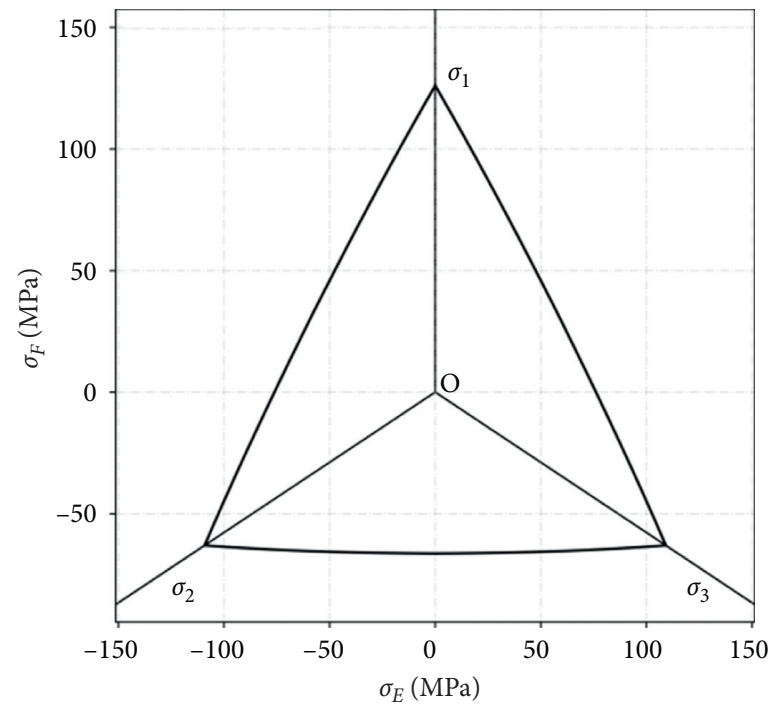

— M-W-1

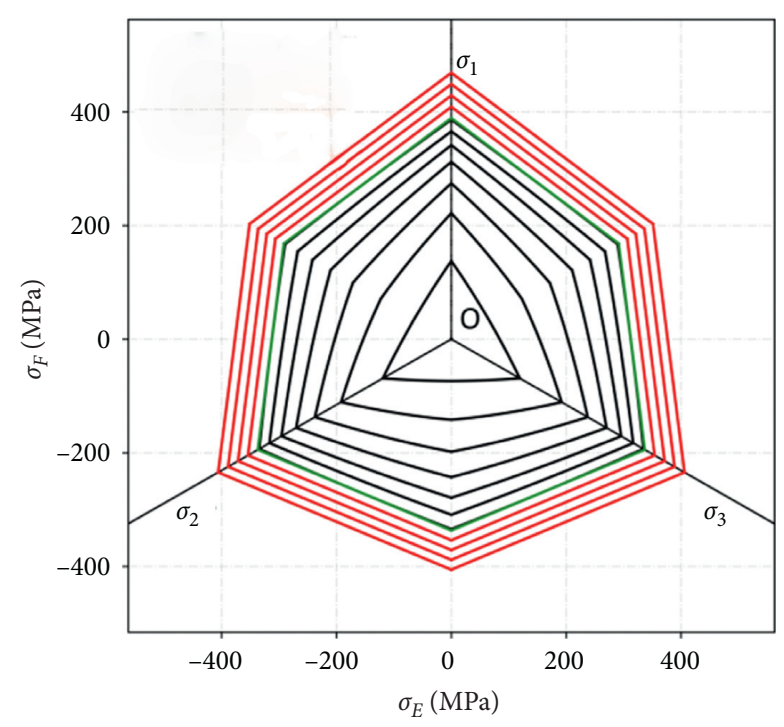

- M-W-1

Interface

— M-W-2

(a)

(b)

Figure 5: The yield surface of the M-W yield criterion on the deviatoric plane. (a) $\pi$ plane $\left(\sigma_{\mathrm{D}}=0\right)$. (b) Sparse yield surface.

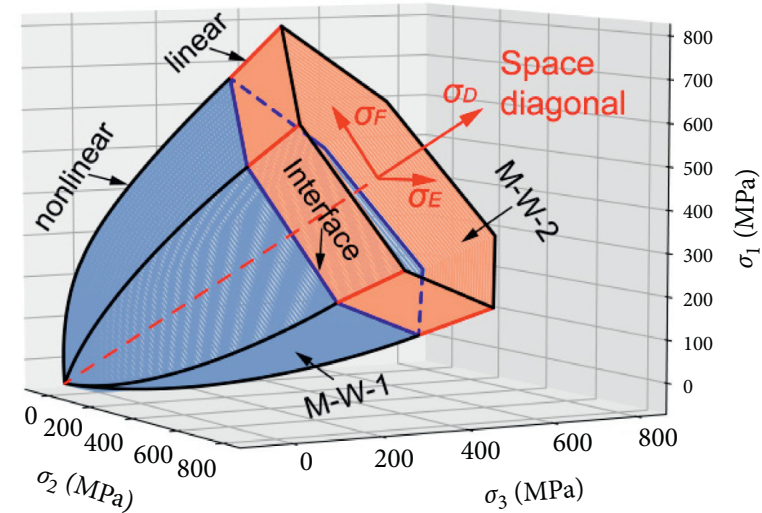

FIGURE 6: The yield surface of the M-W yield criterion in the principal stress space.

TABLE 4: Critical value of the space diagonal.

\begin{tabular}{lccccc}
\hline \multirow{2}{*}{ Rock types } & \multicolumn{2}{c}{$\mathrm{M}-\mathrm{W}$ criterion } & H-B criterion & $\begin{array}{c}\text { M-C criterion } \\
\sigma_{D \min }(\mathrm{MPa})\end{array}$ & $\begin{array}{c}\text { Exp. criterion } \\
\sigma_{D \text { min }}(\mathrm{MPa})\end{array}$ \\
\hline Dunham dolomite & -12.21 & 1184.39 & -60.39 & -144.71 & -63.24 \\
Mizuho trachyte & -3.62 & 569.16 & -35.38 & -91.32 & -24.88 \\
Jinping sandstone & -0.42 & 439.10 & -18.71 & -71.70 & -13.30 \\
Cedar tonalite & -0.31 & 256.22 & -6.15 & -43.86 & -3.35 \\
Carrara marble & -1.59 & 618.99 & -48.17 & -189.31 & -63.83 \\
Westerly granite & -1.11 & 2422.56 & -5.82 & -58.08 & -27.87 \\
Yamaguchi marble & -4.57 & 335.72 & -38.44 & -82.55 & -32.64 \\
Indiana limestone & -7.24 & 121.49 & -29.30 & -77.46 & -17.65 \\
Solnhofen limestone & -93.93 & 509.41 & -197.50 & -439.98 & -126.21 \\
\hline
\end{tabular}


(2) H-B criterion:

(3) Exp. criterion:

$$
\sqrt{6} \sigma_{F}-\sqrt{2} \sigma_{E}=2 \sqrt{m \sigma_{c}\left(\frac{\sigma_{D}}{\sqrt{3}}+\frac{\sigma_{E}}{\sqrt{2}}-\frac{\sigma_{F}}{\sqrt{6}}\right)+\sigma_{c}^{2}}
$$

$$
\sqrt{6} \sigma_{F}-\sqrt{2} \sigma_{E}=2 Q_{\infty}-2\left(Q_{\infty}-Q_{0}\right) \exp \left[-\frac{\left(K_{0}-1\right)}{Q_{\infty}-Q_{0}}\left(\frac{\sigma_{D}}{\sqrt{3}}+\frac{\sigma_{E}}{\sqrt{2}}-\frac{\sigma_{F}}{\sqrt{6}}\right)\right]
$$

The graphing steps on the yield surface of the M-C, H-B, and Exp. are the same as those of $\mathrm{M}-\mathrm{W}-1$. The parameter $\sigma_{D \text { min }}$ of the three criteria (as shown in Table 4) approaches the minimum when $\sigma_{E}$ and $\sigma_{F}$ are equal to zero in equations (35)-(37). The yield surfaces of M-C criterion, H-B criterion, and Exp. criterion are shown in Figures 7-9, respectively. The results show that the intersection of the $\mathrm{M}-\mathrm{C}$ surface with a deviatoric plane is irregularly hexagonal, and $\mathrm{H}-\mathrm{B}$ surface with a deviatoric plane is a nonlinear gradient from triangular towards irregular hexagonal surfaces. The intersection of the Exp. surface with a deviatoric plane is similar to $\mathrm{H}-\mathrm{B}$. In the principal stress space, the $\mathrm{M}-\mathrm{C}$ yield surface varies linearly as a function of $\sigma_{D}$, and the H-B and Exp. yield surfaces vary nonlinearly as a function of $\sigma_{D}$. In addition, the yield curve of $\mathrm{H}-\mathrm{B}$ on the deviatoric plane is a curve of slight curvature, almost equivalent to a straight line [37]. Although the slight curvature is not obvious in Figure $8(\mathrm{a})$, the nonlinearity of the $\mathrm{H}-\mathrm{B}$ criterion is obvious along the axes of $O \sigma_{1}, O \sigma_{2}$, and $O \sigma_{3}$. Similarly, the Exp. yield curve on the deviatoric plane may be a curve of slight curvature because of the nonlinearity of the Exp. criterion. It is worth noting that all four failure criteria are only used for conventional triaxial compression, and deviatoric plane shape in other stress states will be never used.

\section{Comparison}

Taking Solnhofen limestone as an example, four criteria yield surfaces in the principal stress space are shown in Figures 6, 7(b), 8(b), and 9(b), respectively. Considering that the nonlinearity of Exp. criterion is similar to $\mathrm{H}-\mathrm{B}$ criterion, we mainly focus on $\mathrm{M}-\mathrm{C}$ criterion, $\mathrm{H}-\mathrm{B}$ criterion, and $\mathrm{M}-\mathrm{W}$ criterion in the discussion of slope characteristics of yield surface. When $\sigma_{D}=0 \mathrm{MPa}, 200 \mathrm{MPa}$, and $600 \mathrm{MPa}$, three criteria yield surfaces on the deviatoric plane are shown in Figure 10. All vertices occur on the lines of symmetry where two of the principal stresses are equal. The uppermost vertex corresponds to the condition where $\sigma_{1}>\sigma_{2}=\sigma_{3}$, which represents the conventional triaxial compression tests. Figure 10 shows that with the increase of $\sigma_{D}$, the vertices of the three yield surfaces undergo three stages of separation, coincidence, and separation again.

To make that difference more intuitive and less complicated, we set $\sigma_{E}$ to zero and then only consider the yield surfaces with the $\sigma_{D^{-}} \sigma_{F}$ plane as shown in Figure 11, which is a slice through the three-dimensional yield surface shown in Figures $6,7(\mathrm{~b})$, and $8(\mathrm{~b})$. When $\sigma_{F}>0$, the upper yield surfaces correspond to conventional triaxial compression $\left(\sigma_{1}>\sigma_{2}=\sigma_{3}\right)$, which also represents the uppermost vertex as shown in Figure 10. When $\sigma_{F}<0$, the lower yield surfaces correspond to conventional triaxial tensile stress $\left(\sigma_{1}<\sigma_{2}=\sigma_{3}\right)$, which represents the lowermost vertex as shown in Figure 10. Figure 11 shows that the yield surfaces corresponding to the three criteria have a vertex consistent region with increasing $\sigma_{F}$; however, except for the vertex consistent region, the yield state of rock predicted by the three criteria is quite different.

Substituting $\sigma_{E}=0$ into equations (31) and (34)-(37) gives the following:

(1) M-C yield criterion:

$$
\sigma_{F}(3-\sin \phi)=2 \sqrt{6} c \cos \phi+2 \sqrt{2} \sigma_{D} \sin \phi
$$

(2) H-B yield criterion:

$$
\sqrt{6} \sigma_{F}=2 \sqrt{m \sigma_{c}\left(\frac{\sigma_{D}}{\sqrt{3}}-\frac{\sigma_{F}}{\sqrt{6}}\right)+\sigma_{c}^{2}}
$$

(3) Exp. yield criterion:

$\sqrt{6} \sigma_{F}=2 Q_{\infty}-2\left(Q_{\infty}-Q_{0}\right) \exp \left[-\frac{\left(K_{0}-1\right)}{Q_{\infty}-Q_{0}}\left(\frac{\sigma_{D}}{\sqrt{3}}-\frac{\sigma_{F}}{\sqrt{6}}\right)\right]$ 


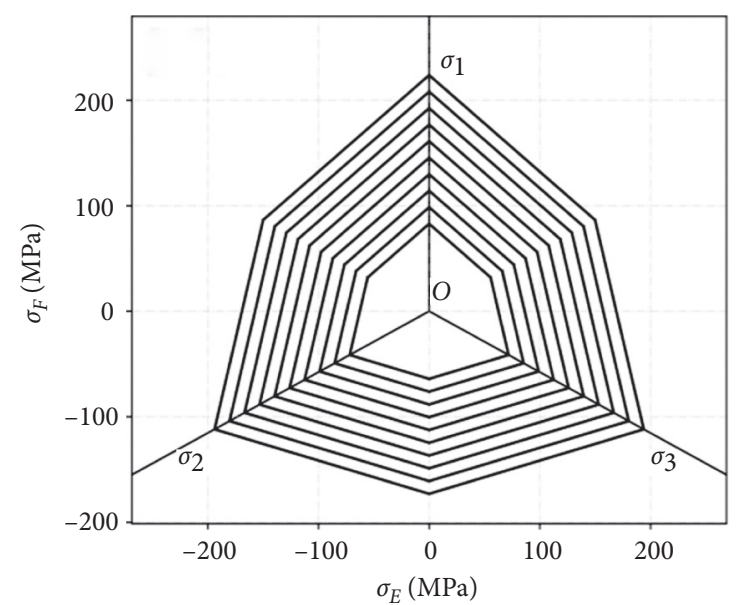

(a)

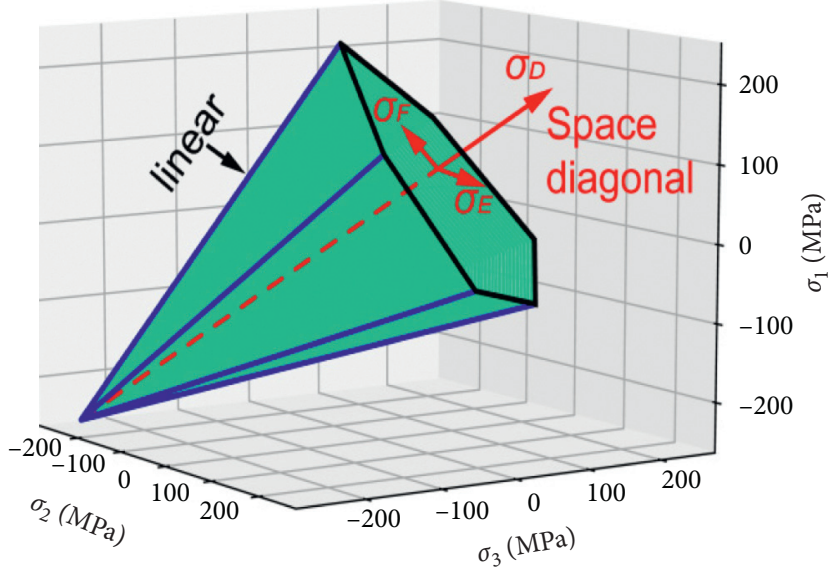

(b)

FIGURE 7: M-C criterion yield surface. (a) Yield surface on the deviatoric plane. (b) Yield surface on the principal stress space.

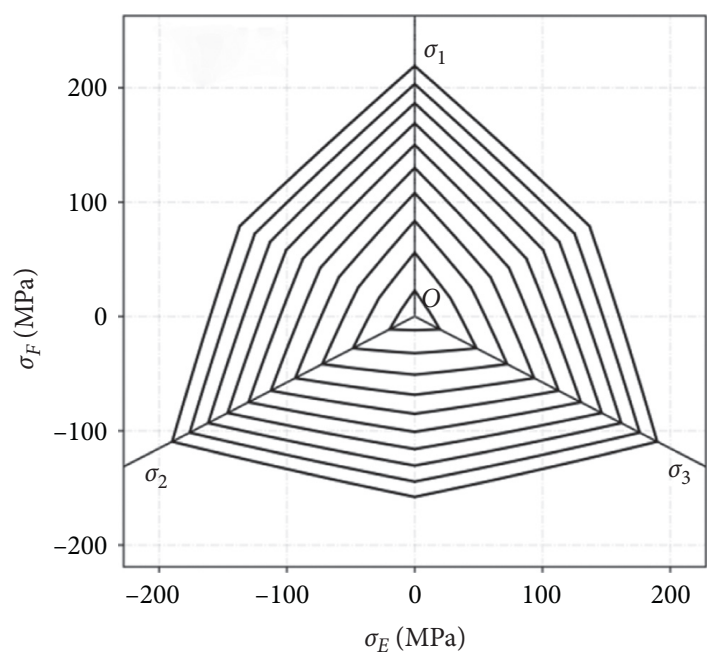

$-\mathrm{H}-\mathrm{B}$

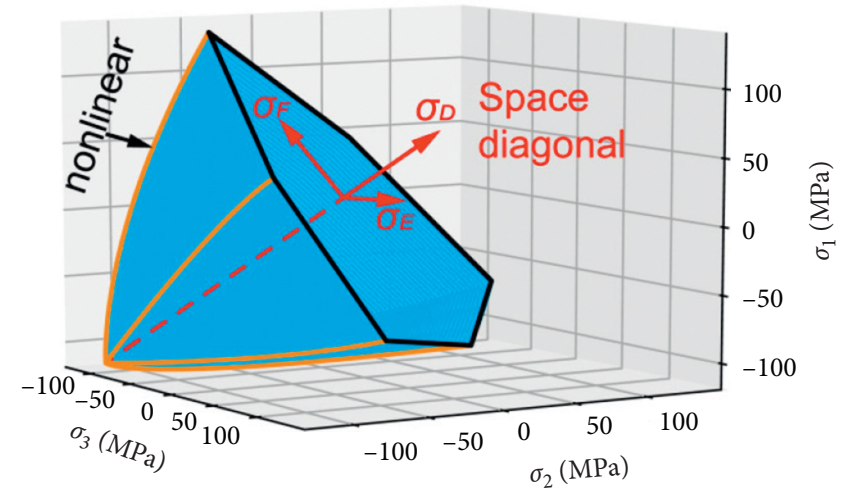

(b)

FIgURE 8: H-B criterion yield surface. (a) Yield surface on the deviatoric plane. (b) Yield surface on the principal stress space.

(4) M-W yield criterion:

$$
\begin{gathered}
\sqrt{6} \sigma_{F}+4 \sigma_{w} \ln \left[\sqrt{1+\left(\frac{\sigma_{t}+(2 / \sqrt{3}) \sigma_{D}+(1 / \sqrt{6}) \sigma_{F}}{2 \sigma_{w}}\right)^{2}}-\frac{\sigma_{t}+(2 / \sqrt{3}) \sigma_{D}+(1 / \sqrt{6}) \sigma_{F}}{2 \sigma_{w}}\right]=2 \sigma_{t}, \\
\sqrt{6} \sigma_{F}\left(3-\cos 2 \Phi^{0}\right)=12 C-4 \sqrt{3} \sigma_{D} \cos 2 \Phi^{0} .
\end{gathered}
$$

That difference depends on the extent of the negative values for $\sigma_{D}$ and the magnitude of the slopes of the yield surfaces. As shown in Figure 11, when $\sigma_{F}=0$, the cohesion and the internal friction angle control the value at the starting point for the $\mathrm{M}-\mathrm{C}$ criterion; the uniaxial compression strength and the experience parameter control the 


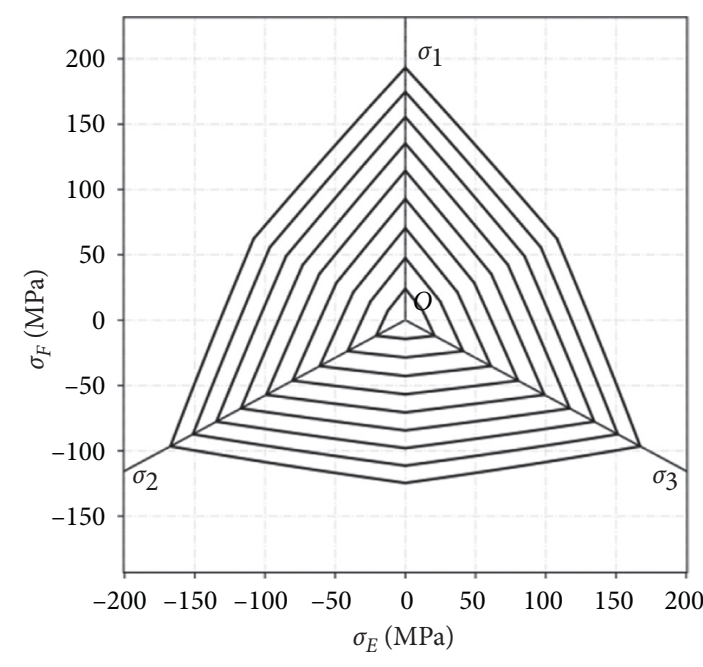

- EXP

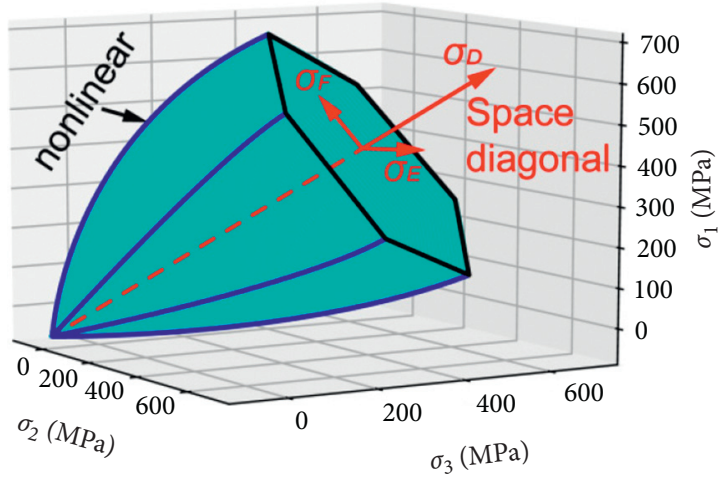

(b)

FIGURE 9: Exp. criterion yield surface. (a) Yield surface on the deviatoric plane. (b) Yield surface on the principal stress space.

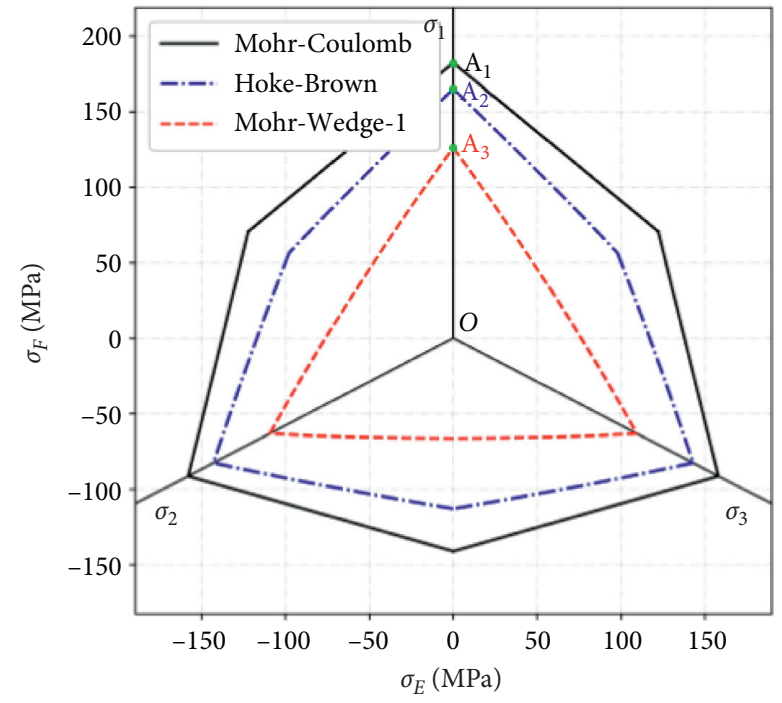

(a)

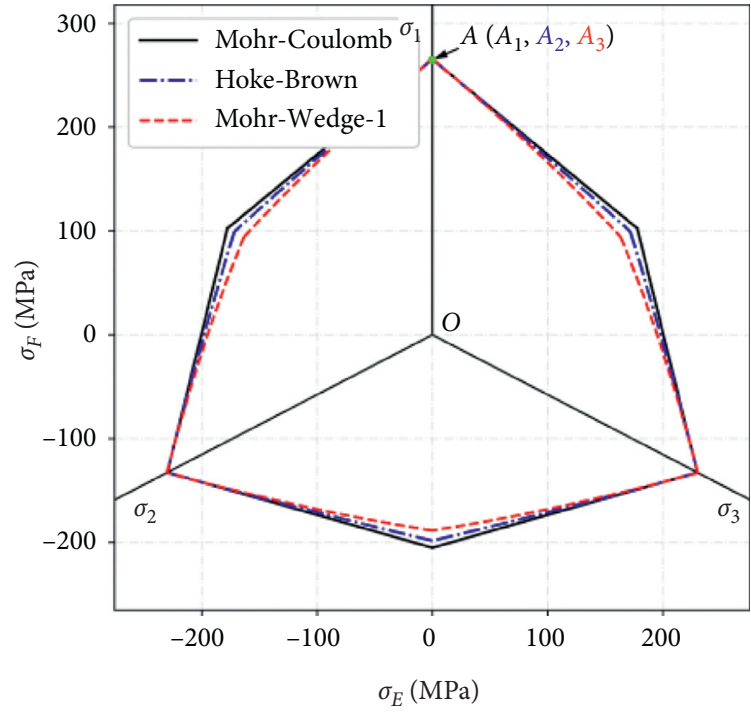

(b)

FIgURE 10: Continued. 


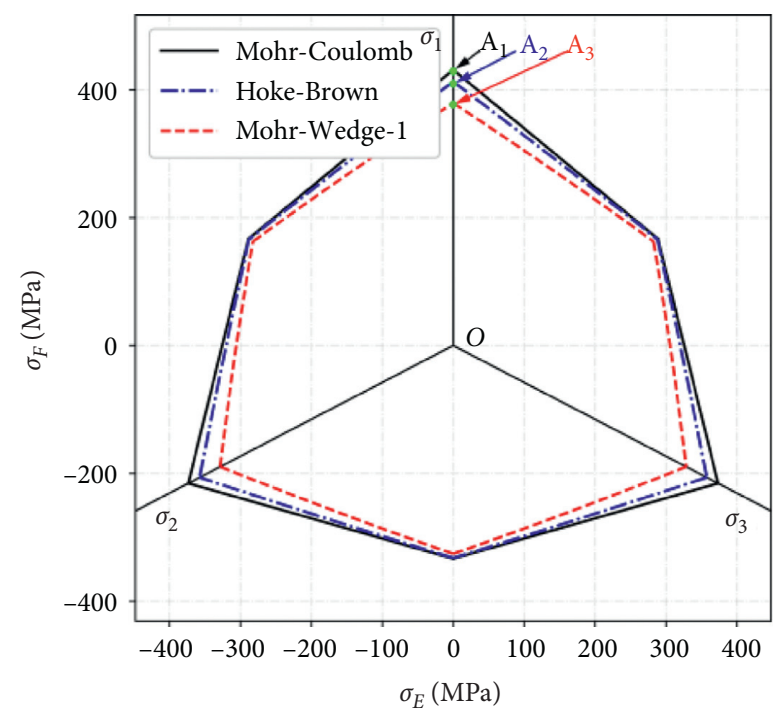

(c)

FIgURE 10: The position relationship of three criteria yield surfaces when (a) $\sigma_{D}=0 \mathrm{MPa}$. (b) $\sigma_{D}=200 \mathrm{MPa}$. (c) $\sigma_{D}=600 \mathrm{MPa}$.

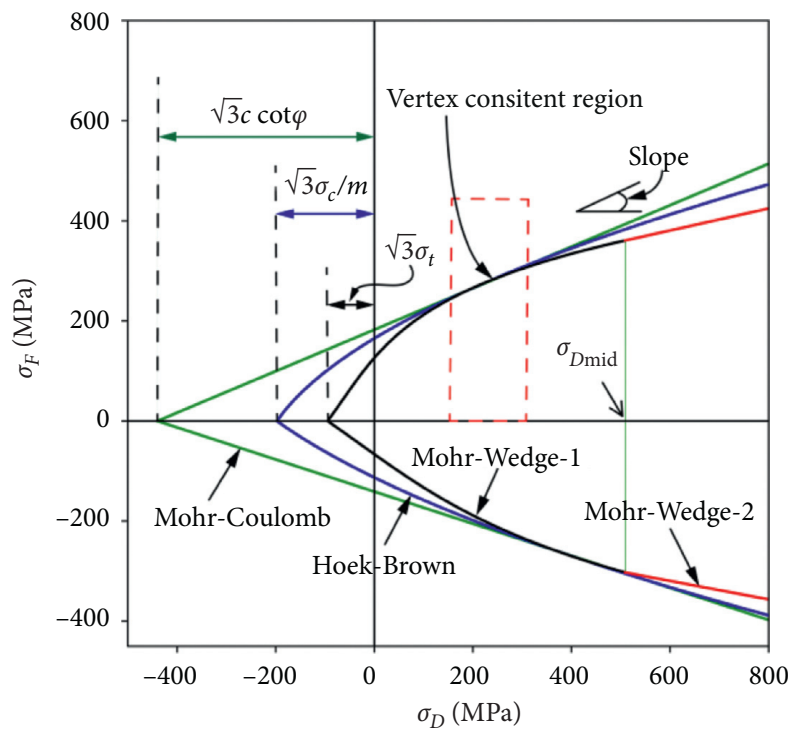

FIGURE 11: The projection of three criteria yield surfaces onto the $\sigma_{\mathrm{D}^{-}} \sigma_{\mathrm{F}}$ plane.

value for $\mathrm{H}-\mathrm{B}$ criterion; and only the uniaxial tensile strength controls the value for the $\mathrm{M}-\mathrm{W}$ criterion. Similarly, the parameters $Q_{0}, Q_{\infty}$, and $K_{0}$ control the value for Exp. criterion according to equation (40). In addition, we can clearly realize the characteristic slopes of the yield surfaces from equations (38)-(42). The slope of the M-C criterion surface is linear. The slopes of the H-B and Exp. criteria surfaces are nonlinear. However, the slope of the $\mathrm{M}-\mathrm{W}$ yield surface is nonlinear, and when $\sigma_{D}>\sigma_{D \text { mid }}$, the slope becomes linear.

Although many factors determine that the four yield surfaces are different, the vertex consistent region may appear due to the increasing value of $\sigma_{D}$. In fact, we exploit the upper yield surfaces on the $\sigma_{D^{-}} \sigma_{F}$ plane to fit the triaxial compression test data from Tables 1 and 2, and the fitting results shown in Figures 12 and 13 suggest the existence of the vertex consistent region. Figure 12 shows the fitting results when the confining pressure is below the critical state, and Figure 13 shows the fitting results when the confining pressure is above the critical state. The results show that four yield surfaces have a vertex consistent region, and within this region, the yield state of rock can be better predicted. However, outside this region, the predicted results of the four yield criteria are different. Therefore, we introduce the relative error $E_{r}$ to estimate the dissimilarity degree. 

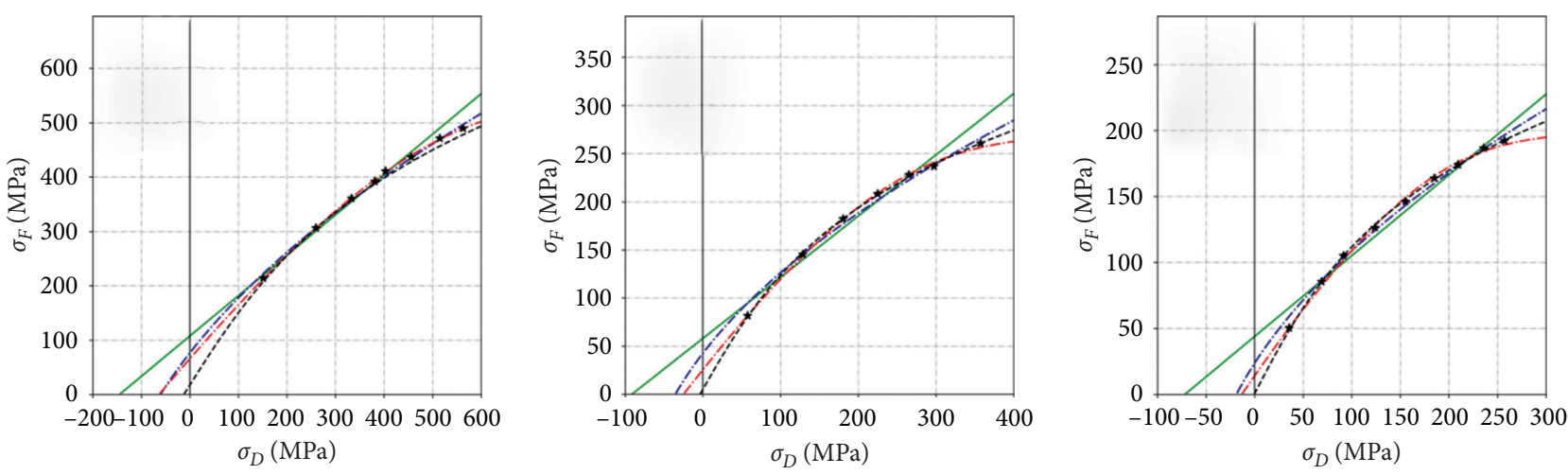

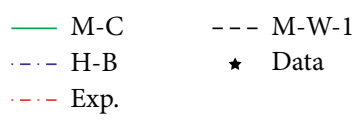

(a)

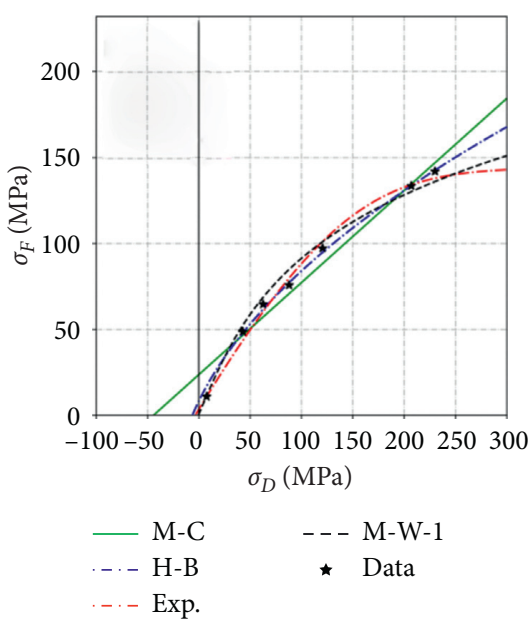

(d)

$$
\begin{array}{ll} 
& \mathrm{M}-\mathrm{C} \\
---\mathrm{H}-\mathrm{B} & \star \mathrm{M}-\mathrm{W}-1 \\
\text {-.- Exp. } &
\end{array}
$$

(b)

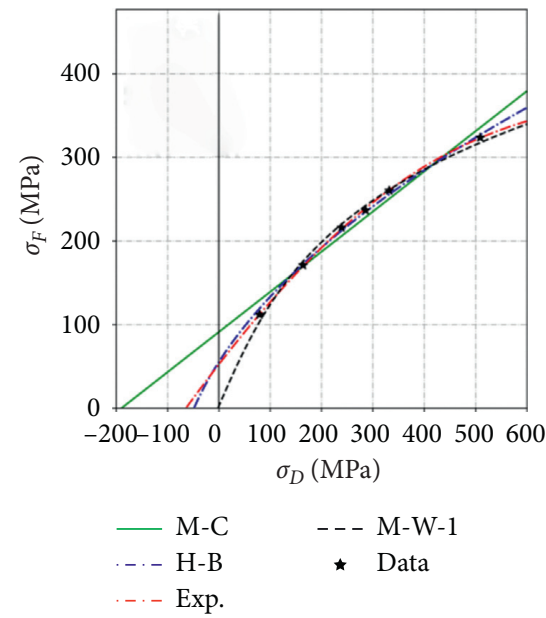

(e)

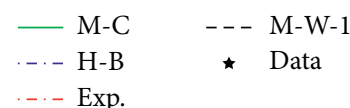

(c)

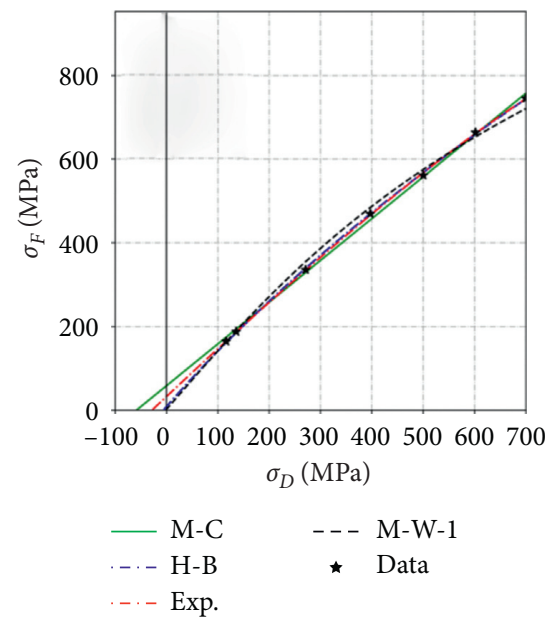

(f)

Figure 12: The yield surfaces on the $\sigma_{D}-\sigma_{F}$ plane: the confining pressure below the critical state. (a) Dunham dolomite. (b) Mizuho trachyte. (c) Jinping sandstone. (d) Cedar tonalite. (e) Carrara marble. (f) Westerly granite.

$$
E_{r}=\frac{\sum_{i=1}^{n}\left|\left(\sigma_{F}^{\text {calc }}-\sigma_{F}^{\text {test }}\right) / \sigma_{F}^{\text {test }}\right|}{n} \times 100 \%,
$$

where $E_{\mathrm{r}}$ is the relative error between the test and calculate, $\sigma_{F}^{\text {test }}$ is the deviatoric stress test data, $\sigma_{F}^{\text {calc }}$ represents the calculated data, and $n$ is the number of triaxial test groups for each rock.

When $\sigma_{3} \leq \sigma_{k}$, the relative errors of the fitting results in Figures 12 and 13 are shown in Figure 14. In terms of the relative error, the $\mathrm{M}-\mathrm{C}$ criterion is higher than the others and the $\mathrm{M}-\mathrm{W}$ criterion is generally lower than the H-B criterion (except the Dunham dolomite). In addition, the relative error values of $\mathrm{M}-\mathrm{W}$ criterion and Exp. criterion are lower than the $\mathrm{M}-\mathrm{C}$ criterion and $\mathrm{H}-\mathrm{B}$ criterion. It is suggested that the $\mathrm{M}-\mathrm{W}$ criterion has certain applicability in predicting the rock yield state under a confining pressure below the critical state.

\section{Discussion}

The $\mathrm{M}-\mathrm{W}$ criterion includes linear and nonlinear sections. In the absence of the derivation process of the yield criterion, the reader can refer to [16]. This study attempted to investigate whether there are differences in predicting the rock yield state for the four yield criteria (M-C, H-B, Exp., and $\mathrm{M}-\mathrm{W}$ criteria). However, as shown in Figure 13, when $\sigma_{D}>\sigma_{D \text { mid }}$, the M-C criterion and $\mathrm{H}-\mathrm{B}$ criterion cannot predict the accuracy of the rock yield state, the Exp. criterion can better predict the Indiana limestone plastic state, and the M-W criterion can better predict the Yamaguchi marble plastic state. In addition, none of them can effectively predict the yield state for Solnhofen limestone when the confining pressure is above the critical state. The possible reason may be related to the ductility of the rock. 


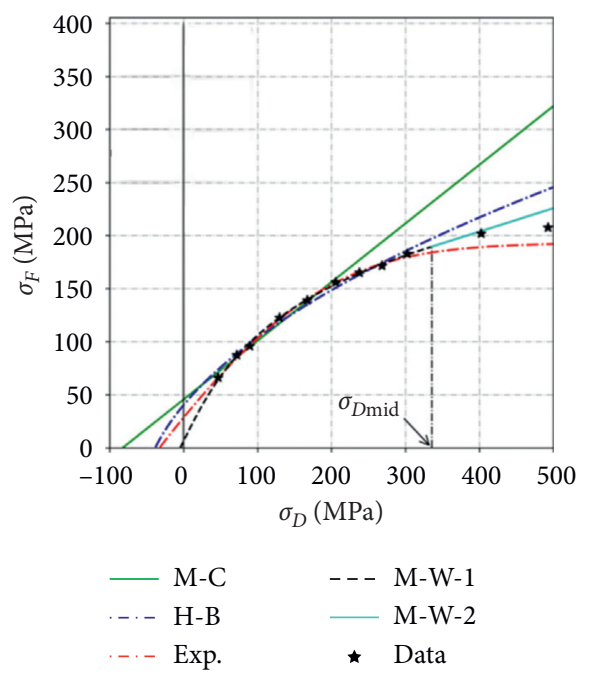

(a)

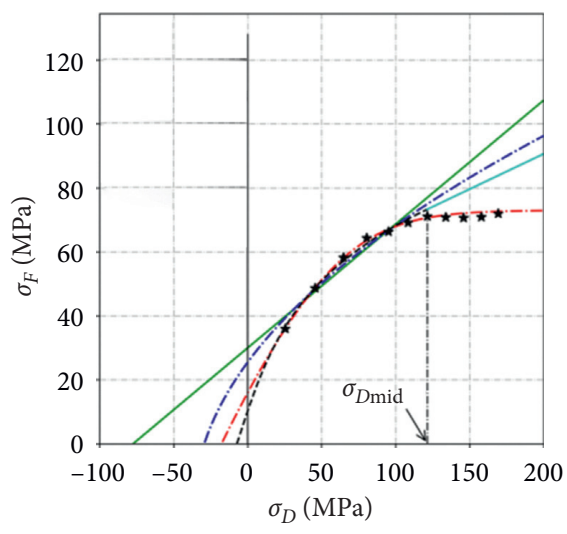

- M-C

-. H-B

- - M-W-1

-.- Exp.

Data

(b)

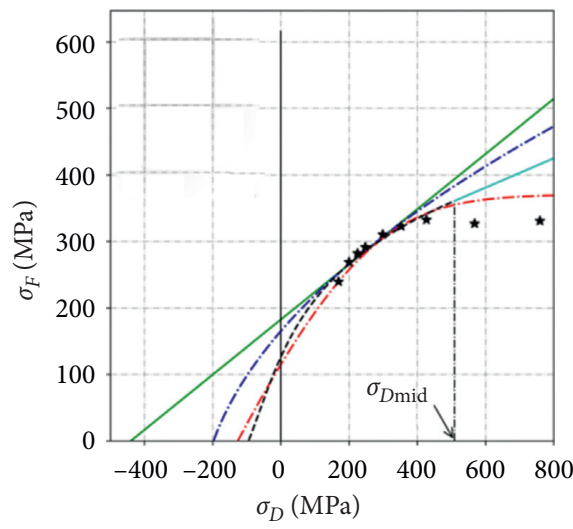

$$
\begin{array}{lll}
- \text { M-C } & -- \text { M-W-1 } \\
-- \text { H-B } & \text { M-W-2 } \\
\ldots-\text { Exp. } & \star \text { Data }
\end{array}
$$

(c)

Figure 13: The yield surfaces on the $\sigma_{D}-\sigma_{F}$ plane: the confining pressure above the critical state. (a) Yamaguchi marble. (b) Indiana limestone. (c) Solnhofen limestone.

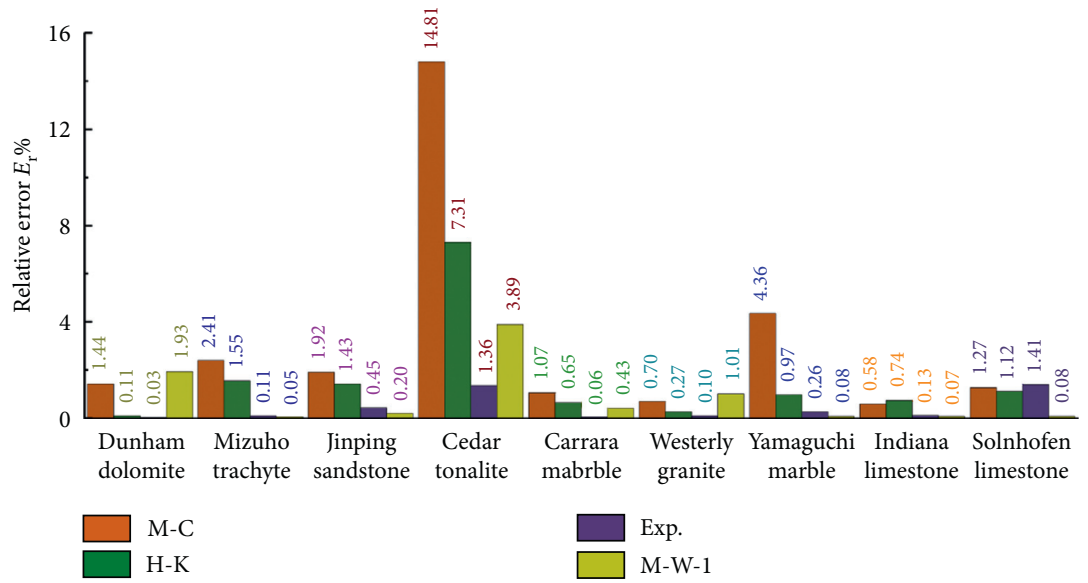

FIGURE 14: Relative error among four yield criteria prediction with test results: all confining pressures below the critical state. 


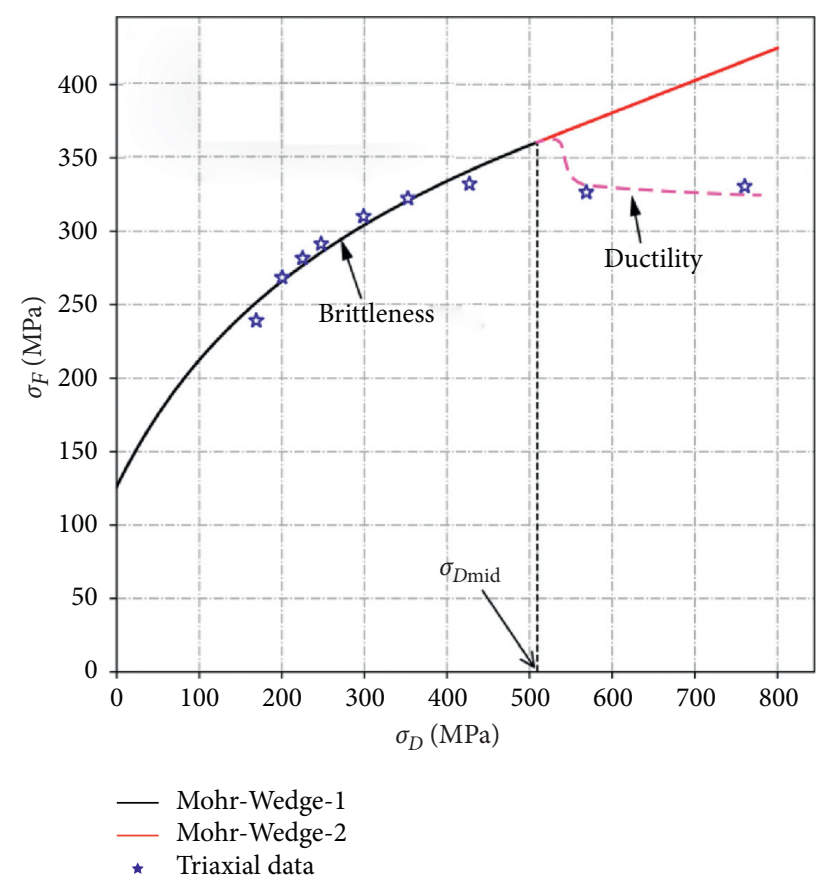

FIGURE 15: The characteristics of the brittleness and ductility for Solnhofen limestone.

The rock strength increases with the confining pressure. The strength growth rate of rock is generally large under the condition of low confining pressure, but with an increase in the confining pressure, the strength growth rate will gradually decrease [22]. Mogi [38] suggested that the fracture behavior of rock changes from brittle to ductile when the confining pressure continues to increase, where the critical confining pressure is assumed to be $\sigma_{c r}$. Hoek [31] proposed that the Indiana limestone transition from the brittleness to ductility stage when $\sigma_{c r}$ is equal to $\sigma_{c}$. Singh et al. [9] analyzed 201 groups of rock triaxial test results to show that the minimum consistent variance was achieved when $\sigma_{c r}$ was approximately equal to $\sigma_{c}$. However, some scholars put forward a different view to the critical confining pressure. $\mathrm{Xu}$ [39] proposed that $\sigma_{c r}$ is approximately equal to $0.85 \sigma_{\mathrm{c}} \sim \sigma_{\mathrm{c}}$ for marble, and Yang [40] suggested that $\sigma_{c r}$ is equal to $0.47 \sigma_{c}$ for marble with medium and coarse grains. In addition, Barton [41] proposed that the critical state is related to the principal stress, namely, $\sigma_{1}=3 \sigma_{3}$.

The different opinions indicate that the critical confining pressure depends on the type of rock, and the value of $\sigma_{c r}$ may not necessarily be related to $\sigma_{c}$. As shown in Figure 13, the slope of Exp. yield curve on the $\sigma_{D}-\sigma_{F}$ plane becomes gently when $\sigma_{D}>\sigma_{D \text { mid }}$, which indicates the critical state proposed in this work is reasonable. It is noteworthy from Figure $13(\mathrm{c})$ that the critical confining pressure $\sigma_{k}$ proposed by the $\mathrm{M}-\mathrm{W}$ yield criterion seems to be related to the transition from brittleness to ductility. Assuming $\sigma_{c r}=\sigma_{k}$, the yield surfaces of the M-W yield criterion can be shown in Figure 15 when $\sigma_{D}>\sigma_{D \text { mid }}$ (namely, $\sigma_{3}>\sigma_{k}$ ), which is only a schematic diagram due to the complex characteristics of rocks in the ductile state. If the ductile characteristics of Solnhofen limestone shown in Figure 15 can be confirmed, we can explain the inaccuracy of Figure 13(c).
Although the M-W yield criterion cannot effectively predict the yield state for Indiana limestone and Solnhofen limestone when $\sigma_{3}>\sigma_{k}$, the parameter $\sigma_{k}$ can be regarded as the critical confining pressure of the rock during the transition from brittleness into ductility. The indicator of the critical confining pressure of more rocks and the expression of criterion on the condition of $\sigma_{3}>\sigma_{k}$ will be studied in future work.

\section{Conclusions}

This study introduced a piecewise rock yield criterion that is a theoretical formula derivation based on microcosmic experiments. Although the actual failure process of the rock may be more complicated than the wedge model, the model is reasonable to a certain extent. When the vertical and horizontal microcracks in the shear potential failure zone of the wedge model are compacted, the failure behavior of the rock enters a critical state. The model accounts for the nonlinear variation in the principal stress when the confining pressure is below the critical state and linear variation in the principal stress when the confining pressure is above the critical state. All of the defining parameters are related to rock damage and can be obtained by a rock axial loading test.

Alternatively, we find that the yield surfaces of different criteria can be obtained through the coordinate transformation of the deviatoric plane and the principal stress space. Then, the rock yield state of the three-dimensional space can be transformed into a two-dimensional plane. Increasing the density of the yield surfaces on the deviatoric plane (namely, the $\sigma_{E^{-}} \sigma_{F}$ plane), the $\mathrm{M}-\mathrm{W}$ yield surface behaves in a nonlinear and linear fashion because of the critical state. Furthermore, we show that different criteria yield surfaces have a vertex consistent region by slicing the 
three-dimensional yield surface along the $\sigma_{D^{-}} \sigma_{F}$ direction. On the $\sigma_{D^{-}} \sigma_{F}$ plane, the fitting results indicate that the $\mathrm{M}-\mathrm{W}$ criterion and the Exp. criterion can predict the rock yield state more accurately than the M-C and $\mathrm{H}-\mathrm{B}$ criteria. This finding suggests that the $\mathrm{M}-\mathrm{W}$ criterion has certain applicability in predicting the rock yield state.

\section{Data Availability}

The data used to support the findings of this study are available from the corresponding author upon request.

\section{Conflicts of Interest}

The authors declare that they have no conflicts of interest.

\section{Authors' Contributions}

Jing Zhang and Fengyu Ren contributed to the formulation of the overarching research goals and aims. Zhihua Ouyang described the criterion features and checked the manuscript. Jing Zhang and Zhihua Ouyang determined the calculation method of criterion parameters. Jing Zhang and Fengyu Ren determined the calculation method of criterion yield surface. Jing Zhang carried out those research methods and wrote the manuscript. Huan Liu contributed to the collection of test data and references.

\section{Acknowledgments}

The support of the Key Program of National Natural Science Foundation of China (Grant no. 51534003) and the National Key Research and Development Program of China (Grant no. 2016YFC0801601) is gratefully acknowledged.

\section{References}

[1] C. Coulomb, "Essai Sur une application des règles de maximis \& minimis à quelques problèmes de statique," in Coulomb's Memoir on Statics, J. Heyman, Ed., Cambridge University Press, Cambridge, UK, 1773.

[2] O. Mohr, "Welche umstande bedingen die elastizitatsgrenze und den bruch eines materials," Zeitschrift des Vereins Deutscher Ingenieure, vol. 44, pp. 1524-1530, 1900.

[3] G. Balmer, "A general analytical solution for Mohr envelope," American Society for Testing and Materials, vol. 52, pp. 1260-1271, 1952.

[4] R. Ucar, "Determination of shear failure envelope in rock masses," Journal of Geotechnical Engineering, vol. 112, no. 3, pp. 303-315, 1986.

[5] P. Kumar, "Shear failure envelope of Hoek-Brown criterion for rockmass," Tunnelling and Underground Space Technology, vol. 13, no. 4, pp. 453-458, 1998.

[6] E. Hoek and E. T. Brown, "Empirical strength criterion for rock masses," Journal of Geotechnical and Geoenvironmental Engineering, GT9, vol. 106, pp. 1013-1035, 1980.

[7] E. HoeK, D. Wood, and S. Shah, J. A. Hudson, A modified Hoek-Brown failure criterion for jointed rock masses," in Proceedings of the Rock Characterization, Symposium of ISRM, pp. 209-214, British Geotechnical Society, London, UK, September 1992.
[8] K. Mogi, "Fracture and flow of rocks under high triaxial compression," Journal of Geophysical Research, vol. 76, no. 5, pp. 1255-1269, 1971.

[9] M. Singh, A. Raj, and B. Singh, "Modified Mohr-Coulomb criterion for non-linear triaxial and polyaxial strength on intact rocks," International Journal of Rock Mechanics and Mining Sciences, vol. 48, no. 4, pp. 546-555, 2001.

[10] A. M. Al-Ajmi and R. W. Zimmerman, "Relation between the mogi and the coulomb failure criteria," International Journal of Rock Mechanics and Mining Sciences, vol. 42, no. 3, pp. 431-439, 2005.

[11] X. Zhou, Q. Qian, and H. Yang, "Strength criteria of deep rock mass," Chinese Journal of Rock Mechanics and Engineering, vol. 27, no. 1, pp. 117-123, 2008.

[12] M. You, "Mechanical characteristics of the exponential strength criterion under conventional triaxial stresses," International Journal of Rock Mechanics and Mining Sciences, vol. 47, no. 2, pp. 195-204, 2010.

[13] H. Rafiai, "New empirical polyaxial criterion for rock strength," International Journal of Rock Mechanics and Mining Sciences, vol. 48, no. 6, pp. 922-931, 2011.

[14] J. Peng, G. Rong, M. Cai, X. Wang, and C. Zhou, "An empirical failure criterion for intact rocks," Rock Mechanics and Rock Engineering, vol. 47, no. 2, pp. 347-356, 2014.

[15] V. Vutukuri, R. Lama, and S. Saluja, Handbook on Mechanical Properties of Rocks, Trans Tech Publications, Clausthal, Germany, 1974.

[16] Z. Ouyang and D. Elsworth, "A phenomenological failure criterion for brittle rock," Rock Mechanics and Rock Engineering, vol. 24, no. 3, pp. 133-153, 1991.

[17] S. Peng and A. M. Johnson, "Crack growth and faulting in cylindrical specimens of chelmsford granite," International Journal of Rock Mechanics and Mining Sciences \& Geomechanics Abstracts, vol. 9, no. 1, pp. 37-86, 1972.

[18] J. Walter, "Failure of granite under compression," International Journal of Rock Mechanics and Mining Sciences and Geomechanics Abstracts, vol. 14, no. 4, pp. 209-215, 1977.

[19] Y. D. Shou, X. P. Zhou, and Q. H. Qian, "A critical condition of the zonal disintegration in deep rock masses: strain energy density approach," Theoretical and Applied Fracture Mechanics, vol. 97, pp. 322-332, 2018.

[20] D. Matthew, P. Joseph, M. Mary et al., "Pseudo-static failure modes and yield accelerations in rock slopes," International Journal of Rock Mechanics and Mining Sciences, vol. 102, pp. 1-14, 2018.

[21] S. Sankhaneel and W. Gabriel, "A progressive S-shaped yield criterion and its application to rock pillar behavior," International Journal of Rock Mechanics and Mining Sciences, vol. 105, pp. 98-109, 2018.

[22] J. Shen, R. Jimenez, M. Karakus, and C. Xu, "A simplified failure criterion for intact rocks based on rock type and uniaxial compressive strength," Rock Mechanics and Rock Engineering, vol. 47, no. 2, pp. 357-369, 2014.

[23] Y. Yang, Y. Lai, Y. Dong, and S. Li, "The strength criterion and elastoplastic constitutive model of frozen soil under high confining pressures," Cold Regions Science and Technology, vol. 60, no. 2, pp. 154-160, 2010.

[24] N. S. Ottosen, Matti, and Ristinmaa, The Mechanics of Constitutive Modeling, Elsevier Science, Amsterdam, Netherlands, 2005.

[25] A. S. Khan and S. Huang, Continuum Theory of Plasticity, John Wiley \& Sons, New York, NY, USA, 1995.

[26] A. Yamaji and K. Sato, "Stress inversion meets plasticity theory: a review of the theories of fault-slip analysis from the 
perspective of the deviatoric stress-strain space," Journal of Structural Geology, vol. 125, pp. 296-310, 2019.

[27] K. Mogi, Experimental Rock Mechanics, Taylor and Francis, London, UK, 2007.

[28] B. Wang, J. B. Zhu, A. Wu et al., "Experimental validation of nonlinear strength property of rock under high geostress," Chinese Journal of Rock Mechanics and Engineering, vol. 29, no. 3, pp. 542-548, 2010.

[29] S. R. Swanson and W. S. Brown, "An observation of loading path independence of fracture in rock," International Journal of Rock Mechanics and Mining Sciences, vol. 8, pp. 277-281, 1971.

[30] T. K. Von, "Festigkeitsversuche unter all seitigem Druck," Zeit Verein Deut Ingr, vol. 55, pp. 1749-1759, 1911.

[31] E. Hoek, "Strength of jointed rock masses," Geotechnque, vol. 23, no. 3, pp. 187-223, 1986.

[32] E. Hoek, "Strength of rock and rock masses," ISRM News Journal, vol. 2, no. 2, pp. 4-16, 1994.

[33] E. Hoek, C. Carranza-Torres, and B. Corkum, "Hoek-Brown criterion - 2002 edition," in Mining and Tunnelling Innovation and Opportunity, R. Hammah, W. Bawden, J. Curran, and M. Telesnicki, Eds., pp. 267-273, University of Toronto, Toronto, Canada, 2002.

[34] E. Hoek and M. S. Diederichs, "Empirical estimation of rock mass modulus," International Journal of Rock Mechanics and Mining Sciences, vol. 43, no. 2, pp. 203-215, 2006.

[35] E. Hoek and E. T. Brown, "The Hoek-Brown failure criterion and GSI-2018 edition," Journal of Rock Mechanics and Geotechnical Engineering, vol. 11, no. 3, pp. 445-463, 2019.

[36] R. O. Davis and A. P. S. Selvadurai, Plasticity and Geomechanic, Cambridge University Press, England, UK, 2002.

[37] J. Clausen and L. Damkilde, "An exact implementation of the Hoek-Brown criterion for elasto-plastic finite element calculations," International Journal of Rock Mechanics and Mining Sciences, vol. 45, no. 6, pp. 831-847, 2008.

[38] K. Mogi, "On the pressure dependence of strength of rocks and the coulomb fracture criterion," Tectonophysics, vol. 21, no. 3, pp. 273-285, 1974.

[39] S. Xu, W. Wu, G. Wang, and e. al, "Study on complete procedures of marble under triaxial compression I: testing study on complete procedure of triaxial compression and the processes of unloading confining at the pre-peak and postpeak," Chinese Journal of Rock Mechanics and Engineering, vol. 20, no. 6, pp. 763-767, 2001.

[40] S. Yang, C. Su, and W. Xu, "Experimental investigation on strength and deformation properties of marble under conventional triaxial compression," Chinese Journal of Rock and Soil Mechanics, vol. 26, no. 3, pp. 475-478, 2005.

[41] N. Barton, "Shear strength criteria for rock, rock joints, rockfill and rock masses: problems and some solutions," Journal of Rock Mechanics and Geotechnical Engineering, vol. 5, no. 4, pp. 249-261, 2013. 